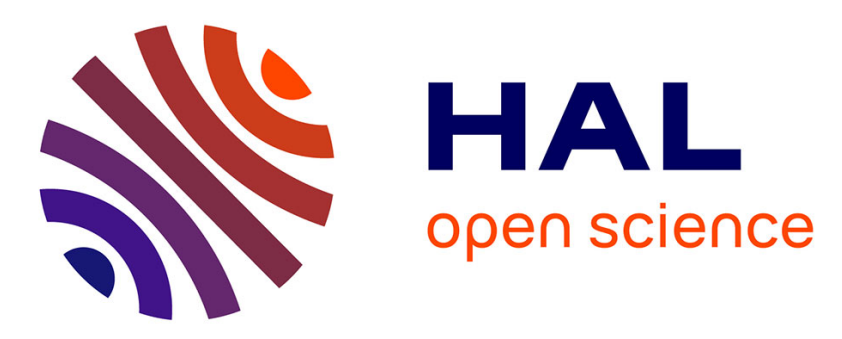

\title{
Modeling of transitional pore blockage to cake filtration and modified fouling index - Dynamical surface phenomena in membrane filtration
}

Bassirou Mahamadou Harouna, Othmane Benkortbi, Salah Hanini, Abdeltif Amrane

\section{To cite this version:}

Bassirou Mahamadou Harouna, Othmane Benkortbi, Salah Hanini, Abdeltif Amrane. Modeling of transitional pore blockage to cake filtration and modified fouling index - Dynamical surface phenomena in membrane filtration. Chemical Engineering Science, 2019, 193, pp.298 - 311. 10.1016/j.ces.2018.07.054 . hal-01894353

HAL Id: hal-01894353

https://hal-univ-rennes1.archives-ouvertes.fr/hal-01894353

Submitted on 15 Oct 2018

HAL is a multi-disciplinary open access archive for the deposit and dissemination of scientific research documents, whether they are published or not. The documents may come from teaching and research institutions in France or abroad, or from public or private research centers.
L'archive ouverte pluridisciplinaire HAL, est destinée au dépôt et à la diffusion de documents scientifiques de niveau recherche, publiés ou non, émanant des établissements d'enseignement et de recherche français ou étrangers, des laboratoires publics ou privés. 
Modeling of transitional pore blockage to cake filtration and modified fouling index - Dynamical surface phenomena in membrane filtration.

\author{
Bassirou Mahamadou Harouna ${ }^{1}$, Othmane Benkortbi ${ }^{1}$, Salah Hanini ${ }^{1}$, Abdeltif Amrane ${ }^{2}$ \\ ${ }^{1}$ Biomaterials and transport phenomena laboratory, (LBMPT). Yahia Fares University, Faculty of Technology, \\ Department of Chemical Engineering and Environment, Ain d'Heb Medea, 26000, Algeria. \\ ${ }^{2}$ Univ-Rennes, Ecole Nationale Supérieure de Chimie de Rennes, CNRS, ISCR - UMR6226, F-35000 Rennes,
} France.

\title{
Abstract
}

The objective of this study was to optimize and to model the membrane fouling process. The modeling was based on two approaches, dynamical and phenomenological with the combination of surface phenomena. The established model was a transitional pore blockage model towards cake fouling through new characteristic parameters and a modified fouling index.

The characteristic parameters developed in this study described the effect of cake restructuring, the shear, the mass of the cake, the filtered fluid recirculation according to the effective thickness $Z_{c}$ in the membrane fouling mechanism. The Modified fouling index Dynamical surface phenomena (MFI- DSP) was developed by characteristics of multiple interactions forces ratio and mechanical forces in the transition of the regime.

The membrane fouling was carried out according to the membrane compressibility factor $\mathrm{m}=$ 1 , the cake $n=[0-1]$ and the kinetics of the fouling process corresponding to the partial orders $\omega=[0-4]$. The new model was validated based on experimental data in tangential and frontal filtration, using PES-10, UE-100 and NF-270 membranes with the prediction of the transitional blockage. Statistical analyzes at CI $\geq 95 \%$ showed better performance and efficiency of the new model compared to the existing models focused on the absolute relative error, the correlation coefficient, the number of characteristic parameters in the prediction, the characterization of the fouling process, as well as in the transition from pore blockage to cake filtration.

Keywords: membrane filtration; fouling process; blocking pore; surface phenomena; Modified-fouling-index; modeling; optimization. 


\section{Introduction}

Several studies focused on the understanding and the controlling of the fouling phenomenon. The various formulations of filtration and characterization of fouling process models followed one another since Darcy's thermal filtration law. The membrane fouling process modeling by several authors, whose Hermia, Schippers and Verdouw, Bassirou et al. and Tien et al. have given rise to models of filtration by pore blocking one hand and other hand the models of filtration on cake by including the surface phenomena and the dynamic of the membrane fouling training by the particles adsorption (Bassirou et al. 2017; Hermia 1982; Schippers and Verdouw 1980; Tien et al. 2014). Developed models for pore blocking showed four characteristic areas of the fouling process in addition to various modified fouling index. In addition, another's studies of Bessierea et al. and Bacchin et al. (Bessierea et al. 2005; Bacchin et al. 2011) allowed to describe accurately the type of the fouling: reversible or irreversible, the mechanism of the membrane fouling and the nature of the fouling compounds. The development of modified fouling index from Schippers and Verdouw (Schippers and Verdouw 1980) the $\mathrm{MFI}_{0.45}$; the UMFI of Hermia and the MFI-UF of Boerlag et al., (Boerlag et al. 2000; Boerlag et al. 2002) is based on the frontal filtration which occupies a wide place in the application of membrane filtration. These indicators do not allow to describe or to understand effectively the obstacle posed by membrane fouling in its variability and evolution. The assessment of fouling using these indicators has been always limited to a single or multiple filtration cycle in the case of $\mathrm{UMFI}_{150}$. The latter, corresponds to the irreversible physical blockage which represents the most worrying problem in the development and the application of membrane technologies, (Huang et al. 2009). This one takes into account, the process of the regime transition and the surface phenomena. However, it is essential to dispose models and modified fouling index allowed characterization several interaction in fouling process for all practical cases for a better understanding and a monitoring of the membrane fouling process consequences. This will take into account, the fouling dynamics, surface phenomena and the transition from the pore blockage towards the cake filtration, (Wang et al. 2012; Xiao et al. 2013). New trends in industrial biotechnologies operating in membrane fermenters made some laws impractical in practice or incompatible with the reality of the membrane system where the membrane fouling takes a large dimension through the inclusion of the biological aspect and surface phenomena, (Albasi-Claire et al. 2007; Huang et al. 2008; Muthukumar et al. 2014). 
Other models of membrane fouling process limited to frontal filtration were proposed considering the simultaneity of fouling phenomena, the association of the fouling with particle size, quantization of fouling by the prediction of the mass deposit, the dynamics of the membrane system, the critical time corresponding to the jump of the transmembrane pressure and the adsorption phenomenon, (Abdelrasoul et al. 2013; Jianrong et al. 2017; Meijia et al. 2018). The complexity of the membrane fouling process with regard to its mechanisms and its characterization tends to reorient the research towards dynamic filtration models based on the analysis of transport phenomena and surface phenomena, (Bassirou et al., 2017; Bacchin et al. 2011; Hermia 1982; Tien et al. 2014). A new modeling technique for membrane filtration processes was proposed by Paipuri et al. (Paipuri et al. 2015). Based on the incompressible fluid flow; it is governed by the Navier-Stokes equation and can be solved using Lattice-Boltzmann technique. The optimization of the process can be studied by following the incompressibility of the membrane and the compressibility of the fouling cake. In the other hand, the low adhesion resistance, surface energies and anticorrosive properties involved in the fouling process can be reduced by increasing the porosity of the cake layer and decreasing the hydrophobic interaction between the membrane surface and the fouling materials. These properties were demonstrated in the case of nanoparticles (Arukalam et al. 2016).

The development and the simulation of the models were based on the description of the relationships between the most relevant variables of the system, such as: the transmembrane pressure $\left(\Delta \mathrm{P}_{\mathrm{m}}\right)$, the inducing effect of the osmotic pressure and the transitional development of the membrane fouling during the filtration, (Albasi-Claire et al. 2007; Huang et al. 2008; Maximous et al. 2010; Wang et al. 2012). Concerning the evaluation of the development of the filter cake, the hypotheses are based on the growth of two layers of the cake, dynamic and static, and this according to a model of linearity " $\mathrm{t} / \mathrm{V}$ " according to the volume "V" (Schippers and Verdouw 1980; Marselina et al. 2009). In a recent study, Haigang et al. developed a fouling process model based on surface phenomena, adsorption (Haigang et al. 2016). The model provides a transition from the adsorption regime (pore blocking) to the cake filtration regime in frontal and in tangential filtration case.

Several authors showed that the standard blocking is in a good agreement with the original membrane flux data as well as the modified membranes during the filtration of sodium alginate (Meijia et al. 2018). They indicated that adsorptive fouling was the main reason for the decline of the flux. Also, they concluded that significant repulsive energy was required to 
overcome fouling process and that lower attractive energy was required for the adsorption of sodium alginate on the surface of the modified membranes, (Jianrong et al. 2017; Li-guo et al. 2015; Li et al. 2016a; Muthukumar et al. 2014). Other authors demonstrated that the cake resistance was the main parameter contributing to the total resistance of the membrane, (Li et al. 2016b; Pradhan et al. 2014).

The major forces contributing to attachment are dispersion interaction force and polar interactions force. These forces apply to material entities at different scales. The resultant force of surface interactions causing fouling can be introduced into the Bassirou et al. logistic cake growth model either as a set of forces acting between three objects or as a pressure reflecting a collective objects behaviour between which interactions exist and the effective osmotic pressure effect mechanism (Bassirou et al. 2017). Jianrong et al. found that membrane surface was randomly rough with obvious fractal characteristics (Jianrong et al. 2017). Quantification of interfacial interaction with randomly rough surface is the prerequisite to quantitatively understand and control the interface behaviours such as adhesion, flocculation and membrane fouling. A novel method, which combines surface element integration method, differential geometry and composite Simpson's rule was developed to quantify the interfacial interactions between the modeled rough floc surface and membrane surface (Xiang et al. 2017). The simulation of the rough membrane surface showed high similarity in terms of statistical roughness and height distribution between the simulated surface and the real membrane surface, indicating feasibility of the new method developed by Xiaolu et al. (Xiaolu et al. 2018). Following the surface interaction force, the thermodynamic analyses released by Li-guo et al. showed that adhesion of sludge flocs on membrane surface needs to overcome a repulsive energy barrier (Li-guo et al. 2015). Under the conditions in their study Xiang et al. assessed, according to thermodynamic methods, interaction energies in three possible interaction scenarios regarding different morphologies (Xiang et al. 2018).

The objective of this study was to propose a new optimized model, based on the approach of the dynamics of membrane fouling and its phenomenology. It was characterized by the blocking of the pores, by the transition of the regime towards the filtration on cake and by an adaptation as well in tangential mode as in frontal mode, using new parameters of fouling process dynamics with a kinetic monitoring and a modified fouling index allowing a better understanding of the various mechanisms. This study allowed to elucidate the involvement of physical parameters such as: the restructuring of the pseudo-membrane, the compressibility of the cake, the recirculation of the fluid and the shear and also that of the physicochemical 
parameters such as the evolution of the fouling material and its dynamics, multiple interactions, the transitional stabilization factor and the characterization of the membrane fouling by the modified fouling index - dynamical surface phenomena MFI - DSP. The model and the MFI - DSP were validated on experimental data by ANOVA analysis, statistical correlation analysis, relative errors and the comparative test of Akaike's Information Criterion (AIC) models.

\section{Materials and Methods}

For the validation of the proposed model as well as the characteristic parameters of the membrane fouling and the membrane filtration, the data processed in this work were obtained from the work of Bouchard and Tamas 2004. The statistical processing of the data was carried out on the Origin Pro ver 8 software and all the calculations were done on Excel 2016. The validation tests of the model were carried out according to the point distribution function Fvalue, the probability of the error on the function Pro> F, the accuracy of the model, the reduction of the absolute relative error, the correlation coefficient R-square and Adj.R-square and the AIC test to compare the performance of the new proposed model with those existing in the literature, (Bassirou et al. 2017).

The membrane NF-270 was of composite type, the active layer was made of polyamide / polysulfone with a cut-off and a permeability of $300 \mathrm{Da}$ and of $k_{p}=3.54 \times 10^{-11}(\mathrm{~m} / \mathrm{Pa} . \mathrm{s})$ respectively. The loss area of the permeability for this membrane is $k_{p}=[3.14-3.97] \times 10^{-11}$ (m/Pa.s), with the maximum operating pressure and the temperature were $21 \%, 41.0$ bar and $40^{\circ} \mathrm{C}$ respectively, the interval of $\mathrm{pH}$ ranging from 2 to 11 and that of washing varying from 1 to 12 .

The membrane PES-10 was a polyethersulfone membrane with a cut-off and a permeability of $10 \mathrm{kDa}$ and $k_{p}=1.92 \times 10^{-10}$ (m/ Pa.s) respectively. For this membrane, the loss area of permeability is $k_{p}=[1.63-2.15] \times 10^{-10}(\mathrm{~m} / \mathrm{Pa} . \mathrm{s})$, with the maximum operating pressure and the temperature were $24 \%, 13.8$ bar and $60{ }^{\circ} \mathrm{C}$, respectively. The operating $\mathrm{pHs}$ ranging from 2 to 11 and those of washing from 1 to 13 .

The frontal ultrafiltration membrane UE-50 was made of polyethersulfone with a cut-off and a permeability of $100 \mathrm{kDa}$ and of $k_{p}=3.64 \times 10^{-10}$ (m/Pa.s) respectively. The loss area of permeability was maintained between $40-60 \%$ in the area $k_{p}=[3.09-4.19] \times 10^{-10}(\mathrm{~m} / \mathrm{Pa} . \mathrm{s})$. 
The maximum operating pressure and the temperature were 13.8 bar and $45^{\circ} \mathrm{C}$ respectively. The operating $\mathrm{pHs}$ ranging from 2 to 11 and those of washing from 1 to 13 .

In addition, the experimental conditions were fixed as follows: the transmembrane pressure, $\Delta \mathrm{P}_{\mathrm{m}}=2 \times 10^{5} \mathrm{~Pa}$, the maximum volume filtered from the tank, $\mathrm{V}=20 \mathrm{~L}$, the temperature, $\mathrm{T}=$ $25{ }^{\circ} \mathrm{C}$, the water conductivity, $\mathrm{k}$ varying between 29 and $584 \mu \mathrm{S} / \mathrm{cm}$ and the $\mathrm{pH}$ in the range of $=[6.20 ; 7.71]$. Otherwise, the ionic composition of the water was $[0.23 ; 3.07] \mathrm{mg} / \mathrm{L},[1.16$; $44.63] \mathrm{mg} / \mathrm{L}$ and $[0.62 ; 16.14] \mathrm{mg} / \mathrm{L}$, for Iron, Calcium and Magnesium respectively.

\subsection{Pore blocking model}

The new proposed membrane fouling model is based on assumptions describing: pore blocking models, Hermia 1982, equation (1), the model proposed by Jaffrin et al. 1997 equation (2), and the model of Tien et al. 2014 equation (3). The proposed kinetic equation of the filtration follows the structure of the models described by these authors which shows the four characteristic mechanisms of membrane pore blockage fouling such as: standard, intermediate, complete blockage and the cake formation on the surface of the membrane.

$\frac{1}{V}=\frac{1}{Q_{p o} t}+\frac{K_{s}}{2}$

$J_{p}=J_{p o}\left(1-\frac{\beta J_{p o} t}{\delta \varepsilon}\right)$

$\frac{d^{2} t}{d V^{2}}=k\left(\frac{d t}{d V}\right)^{n}$

\subsection{New transitional blocking pores model formulation}

The formulation of the new model focused on the characterization of the hydrodynamics and the phenomenology of membrane fouling process through the transport phenomena. The latter, combining the multiple interactions in the system (particles / particles and particles / walls) contribute to membrane fouling, (Jianrong et al. 2017; Tien et al. 2013; Xiang et al. 2017). The objective was to lead to a formulation based on the two approaches in order to optimize the filtration process, to define the different phases of fouling process and the transition regime from the pore blocking towards the cake filtration, (Muthukumar et al. 2014; Xiao et al. 2013).

In the case of the incompressible cake filtration, Darcy's law showed a linear relationship between " $t / \mathrm{V}$ versus $\mathrm{V}$ ". When the cake becomes compressible, "t/V" is independent of " $\mathrm{V}$ " 
and the relation is no longer linear. This loss of linearity is a characteristic of the jump of transmembrane pressure. The work conducted by Robles et al. and Zhang et al. (Robles et al. 2013; Zhang et al. 2015) showed that the development of the cake layer is limited by the ratio between the shear forces and the adhesion/deposition mechanisms of the materials to the membrane (Han et al. 2017; Jianrong et al. 2017, Xiang et al. 2018; Xiaolu et al. 2018). Equations (4) and (5) represent the relationship between the filtered volume and the filtration time.

$a V^{2}+b V-t=0$

Equation Eq.4 is the model formulated by Schippers and Verdouw 1980 from the Darcy and Schirato model on thermal ultrafiltration. The major difference in this study is the presentation of the architecture of this model without defining the parameters characterizing the clogging in order to have the possibility of using the model in the rest of our formulation with $a, b$ : are the intrinsic parameters of the filtration process defining the characteristics of the fouling nature.

$\frac{t}{V}=\frac{\mu \alpha M E S}{2 S^{2} \Delta P m} V+\frac{R_{m} \mu}{S \Delta P m}$

By considering the expression of the pressure loss formulated by Ergun 1952, on a system animated with an initial velocity according to the thickness of the developed wall, it has been demonstrated that the dissipation of the kinetic energy is due to the flow of the fluid through the porous medium (cake - membrane) resulting from the applied pressure drop, which represents the flow rate of the fluid according to the volume of the suspension passing through the membrane. The law related to the loss of the load of Ergun 1952 is given by equation (6).

$A U^{2}+B U+\frac{\Delta P}{Z}=0$

The speed of the flux passing through the medium is given by equation (7)

$U=\frac{1}{S} * \frac{V}{t}$

The thickness $\mathrm{Z}$ of the membrane combined with that of the fouling deposit can be expressed according to the integral below equation (8), according to the Bassirou et al. logistic cake growth model of tangential filtration on cake proposed in last study (Bassirou et al. 2017). The thickness of the cake $Z_{c}$ was obtained by combining equations of Lodge et al. 2004 and 
Marselina et al. 2009, equations (18) and (19), and then substitution in the expressions (20) and (21); the results were expressed according to the flow rate of permeation following the transition process of the hydrodynamic regime. The corresponding expression (22) defining $\mathrm{Zc}$ (Cake thickness) was compared with the integral equation (8) and the result was correlated between equation (8) and (22).

$Z=Z_{m}+\int_{0}^{t} Z_{c}(t) d t$

The combination of equations (4) and (7) and the substitution of the pressure gradient in equation (4) allow to establish the relationship between the volume, the pressure drop, the filtration time and the thickness (equation (9)).

$V=\left(\left(-\frac{b \Delta P}{Z}+\frac{150(1-\varepsilon)^{2}}{S \varepsilon^{3}} \frac{\mu}{d_{p}^{2}}\right) t\right)\left(\left(a \Delta P \frac{t}{Z}-\frac{1,75(1-\varepsilon) \rho}{\varepsilon^{3} d_{p} S^{2}}\right)^{-1}\right)$

Equation (9) can be expressed in the form of " $1 / \mathrm{V}$ versus $1 / \mathrm{t}$ " describing the kinetics of poreblocking filtration, according to the similar assumptions of Hermia. Equation (10) constitutes the basis of the new model following the two approaches of this modelization.

$\frac{1}{V}=\frac{\beta}{\alpha}-\frac{\theta}{\alpha} * \frac{1}{t}=\frac{\mu \alpha M E S}{2 S\left(\left(\frac{150(1-\varepsilon)^{2} \mu}{\varepsilon^{3} d_{p}^{2}}\right) Z-\frac{R_{m} \mu}{S \Delta P m} S \Delta P\right)}-\frac{(1,75(1-\varepsilon) \rho) Z}{\varepsilon^{3} d_{p} S\left(\left(\frac{150(1-\varepsilon)^{2} \mu}{\varepsilon^{3} d_{p}^{2}}\right) Z-\frac{R_{m} \mu}{S \Delta P m} S \Delta P\right)} \frac{1}{t}$

\subsection{Dynamical approach of the fouling process}

The dynamic approach of the membrane fouling process modeling is based on both optimization of the pore-blocking filtration, and transition process of the regime through the two compressibility factors of the membrane " $m$ " and the cake " $n$ " (Muthukumar et al. 2014; Xiao et al. 2013). These values are predicted by maintaining the dimensional homogeneity of equation (10) on the one hand and to obtain a related description of the cake filtration phenomenon on the other hand. Thus, the mean values of " $n$ " and " $m$ " are determined for each filtration case and then for all the processed data in order to generalize them, equation (11).

$\left(\frac{1}{V}\right)^{m}=\frac{\beta}{\alpha}-\frac{\theta}{\alpha}\left(\frac{1}{t}\right)^{n}$

\subsection{Parametric studies}

The parameters that allow to optimize the process and to obtain the transitional characterization of the model are determined using Kozeny-Carman expression and the 
general expression of Ergun (Ergun 1952). From the equation (12) of Kozeny-Carman, ( $\alpha$ ), represents the hydraulic resistance of the cake according to the properties of the matrix such as the compressibility, the chemical composition, the particle size and the transmembrane pressure, (Lodge et al. 2004). The general expression of Ergun is given by equation (13).

$\alpha=\frac{180(1-\varepsilon)}{\rho_{p} d p^{2} \varepsilon^{3}}$

$\frac{\Delta P}{H}=\left(\frac{150(1-\varepsilon)^{2}}{\varepsilon^{3}} \frac{\mu}{d_{p}^{2}}\right) U_{0}+\left(\frac{1,75(1-\varepsilon) \rho}{\varepsilon^{3} d_{p}}\right) U_{0}^{2}$

The combination of equations (12) and (13) allows to rearrange the expression (11) in order to obtain the expression (14) which is a characteristic of the membrane filtration process according to the combinatorial hypotheses of the transport phenomena and the multiple interactions involved in the process of fouling inside the pores and on the surface of the membrane, (Jianrong et al. 2017, Tien et al. 2013, Xiang et al. 2017).

$\left(\frac{1}{V}\right)^{m}=\left(\frac{\rho Z}{\mu S}\left(\frac{1,75 d_{p}(1-\varepsilon)}{150(1-\varepsilon)^{2} Z-R_{m} d_{p}^{2} \varepsilon^{3}}\right)\right)\left(\frac{1}{t}\right)^{n}+\frac{\alpha M E S\left(\varepsilon^{2} d_{p}^{2} \Delta P_{m}\right)}{300(1-\varepsilon)^{2} Z \Delta P_{m} S-2 R_{m} d_{p}^{2} \varepsilon^{3}}$

By studying the hydrodynamics of the fouling process according to the time and the monitoring of the forces ratio considered in the new formulation of the proposed model, a dimensionless factor $\Psi$ given by equation (15) has been defined in the range of [0-1]. It characterizes the restructuring of the physicochemical properties of the pseudo-membrane (fouling cake) and the surface properties of the membrane. Its role is to take into account the variations of the overall properties of the filter matrix, (Mondal et al. 2010; Xiao et al. 2013; Zhao et al. 2013). During the filtration process, $\Psi$ characterizes the phenomenological changes that condition the evolution of the fouling cake with an additional total resistance $\left(R_{T}\right.$ $=\mathrm{R}_{\mathrm{m}}+\mathrm{R}_{\mathrm{c}}$ ), (Pradhan et al. 2014; Robles et al. 2013).

$\Psi=\frac{1,75 d_{p}(1-\varepsilon)}{150(1-\varepsilon)^{2} Z-R_{m} d_{p}^{2} \varepsilon^{3}}$

Equation (16) was obtained by combining equations (14) and (15); it represents the kinetics of the filtration.

$\left(\frac{1}{V}\right)^{m}=\left(\frac{\rho Z}{\mu S} \Psi\right)\left(\frac{1}{t}\right)^{n}+\frac{\alpha M E S}{Z_{m}}\left(\frac{\varepsilon^{2} d_{p}^{2} \Delta P_{m} Z}{300(1-\varepsilon)^{2} Z \Delta P_{m} S-2 R_{m} d_{p}^{2} \varepsilon^{3}}\right)$

\subsection{Phenomenological approach of fouling}


The phenomenological approach in this modeling follows the basic assumptions of the first dynamic approach. A shear factor $\beta$ has been defined, characterizing the ratio of the shear forces due on the one hand to the movement of the particles in the vicinity of the membrane surface and on the other hand to all the external forces involved in the membrane fouling as function of the variations of the transmembrane pressure and following the formation of the fouling cake, equation (17), (Zhang et al. 2015).

It characterizes the different mechanisms of membrane fouling process according to the kinetics of partial order $\omega$ described by the new model. This model was established by applying the pressure drop equations of Ergun, the resistance of the cake of Lodge et al., the hydraulic resistance of Marselina et al. and that of Kozeny-Carman. The reorganization of equation (16) leads to the equation (18) followed by the equation (19).

$$
\begin{aligned}
& \beta=\frac{\varepsilon^{2} d_{p}^{2} \Delta P_{m} Z}{300(1-\varepsilon)^{2} Z \Delta P_{m} S-2 R_{m} d_{p}^{2} \varepsilon^{3}} \\
& \left(\frac{1}{V}\right)^{\mathrm{m}}=\left(\frac{\rho \mathrm{Z}}{\mu \mathrm{S}} \Psi\right)\left(\frac{1}{\mathrm{t}}\right)^{\mathrm{n}}+\frac{\alpha \mathrm{MES}}{\mathrm{Z}_{\mathrm{m}}} \beta \\
& \left(\frac{1}{\mathrm{~V}}\right)=\left(\frac{\rho \mathrm{Z}^{2} \Psi}{\mu\left(\mathrm{ZS}-\alpha \mathrm{M}_{\mathrm{c}} \mathrm{S}^{2} \beta\right)}\right)\left(\frac{1}{\mathrm{t}}\right)^{\omega}
\end{aligned}
$$

The restructuring factors of the pseudo-membrane $\Psi$ and the shear $\beta$ are determined from equations (20) and (21).

$$
\begin{aligned}
& M_{c}=\left(\frac{Z}{\alpha S \beta}\right)-\left(\frac{\rho Z^{2} \Psi}{\mu S^{2} \alpha \beta}\right)\left(\frac{V}{t}\right) \\
& \Phi=\left(\frac{M_{c(i)}-M_{c(n)}}{M_{c(i)}}\right)
\end{aligned}
$$

\subsection{Prediction and fouling mechanism characterization}

The new proposed model describes the phenomenon of the membrane fouling process according to four successive phases (Fig. 1):

1. the fouling is carried out by blocking the pores under the action of the mechanical forces which entrains the particles inside the pores, 
2. the intermediate pore blocking, characterized by multiple interaction forces between the particles that condition the adsorption phenomenon of the particles inside the pores and on the membrane wall, (Bacchin et al. 2011),

3. the fouling occurs by a complete blocking pores,

4. the formation of an incompressible cake on the surface of the membrane.

This, results in an accumulation of material on the membrane surface, a decrease in the flux of permeation, causing a jump in the transmembrane pressure, (Bassirou et al. 2017; Haigang et al. 2016; Jaffrin et al. 1997; Muthukumar et al. 2014; Pradhan et al. 2014). Depending on the evolution of the membrane fouling process, the result is an effect of the association of the physicochemical properties of the cake with those of the membrane. This generates a cake resistance $R_{c}$, a specific hydraulic resistance $\alpha$ and a variation of the overall thickness of the pseudo-membrane and the particle adhesion to the wall, (Han et al. 2017; Jianrong et al. 2017, Xiang et al. 2018; Xiaolu et al. 2018).

By combining equations of Lodge et al. and Marselina et al. equations (18) and (19), it is possible to express the mass of the cake $\mathbf{M}_{c}$ according to the flow rate of permeation following the transition process of the hydrodynamic regime expressed by equation (20), ( Lodge et al. 2004 and Marselina et al. 2009). The thickness of the cake $Z_{c}$ is given by equation (22):

$Z_{c}=\left(\frac{\mu S}{\rho Z \Psi}\left(1-M_{c} \alpha S \beta\right) \Phi\right)\left(\frac{t}{V}\right)$

In order to follow the evolution of the thickness $Z_{c}$ of the cake, fouling the membrane against the mass $\mathrm{M}_{\mathrm{c}}$ and the shear factor $\beta$, the equation (22) is affected by a fluid recirculation factor $\Phi$ characterizing the level of the settlement of the cake, (Comiti and Renaud 1989). 

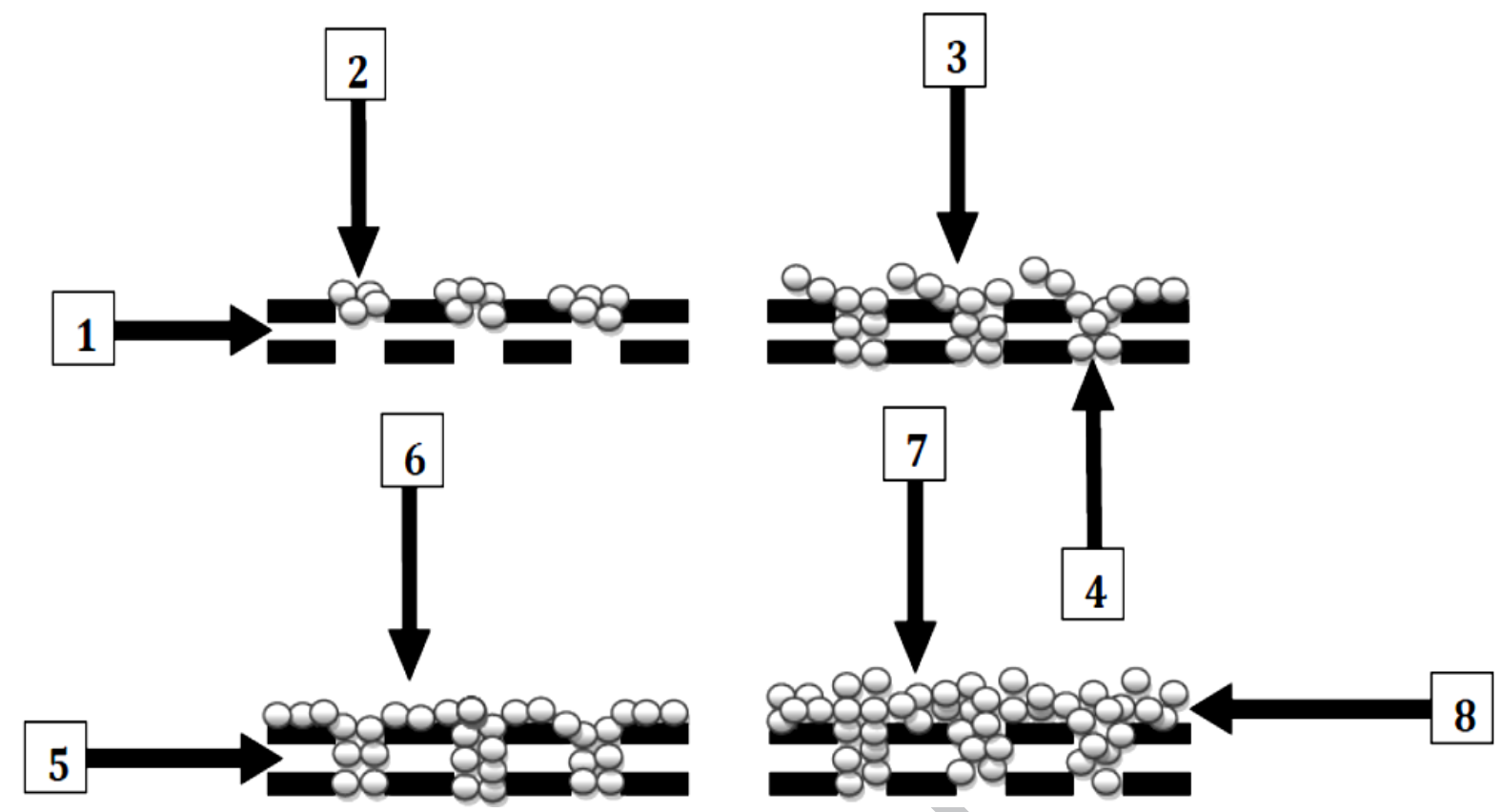

Figure 1: Prediction of the fouling mechanism by the new block pore model. (1) porous membrane ; (2) pores blocks ; (3) intermediate pores blocks ; (4) Internal pores adsorption ; (5) completes pores blocks ; (6) incompressible cake training ; (7) cake compressing; (8) particles accumulate by surface membrane interaction.

\subsection{Modified fouling index development (MFI - DSP)}

Since the development of the modified fouling index $\left(\mathrm{MFI}_{0,45}\right)$ by Schippers and Verdouw according to the SDI method, several authors proposed various modified fouling index for pore blocking and for cake filtration in frontal mode, Hermia (UMFIT), Boerlag et al. (MFIUF), Huang et al. (UMFI), Sergio et al. (MFI-UF constant-flow), (Boerlag et al., 2000 and 2002; Hermia 1982; Huang et al. 2008; Schippers and Verdouw 1980 and Salinas-Rodriguez et al. 2015).

Other indicators, (CFS-MFI) of Javeed et al. correlated with $\mathrm{MFI}_{0,45}$ by Koo et al. (CFI) of Yongxun et al. (multiple MFI) Younggil et al. and its application by Yongxun et al. allowed to describe the characteristics and the nature of fouling without taking into account the transitional phenomenon of the regime and the surface phenomena in the membrane filtration. Bassirou et al. and $\mathrm{Ki}$ et al. and reported in their studies, the effect of the dynamics of the surface phenomena on the membrane fouling process (Bassirou et al. 2017; Koo et al. 2014; Javeed et al. 2009; Jee et al. 2016; Yongxun et al. 2015; Younggil et al. 2015; Yongxun et al. 2017). 
According to the principle described by Bassirou et al. and Wang et al. a new indicator, called modified fouling index dynamical surface phenomena (MFI-DSP) was proposed in this study in order to take in consideration the problem of the regime transition at all scales of filtration and the importance of surface phenomena in the case of inorganic and organo-mineral membranes (Bassirou et al. 2017; Wang et al. 2012). It allowed to characterize the fouling according to the dynamics of the surface phenomena of the membranes PES combined with the transport phenomena following the hypothesis of the transient regime of the permeation flux. The global flow is the result of three distinct and interactive flows characterized by the capillarity, the solubilization and the diffusion (Fig.2), (Bassirou et al. 2017; Zhao et al. 2013).

It defines the membrane fouling by blocking the membrane pores according to the four main phases, followed by the fouling by formation of the incompressible cake and finally the fouling by compressible cake. Considering, the laws established by Bassirou et al. (equations (23) and (24)) and by substituting the flow of the equation (20) in the equation (23), equations (25 and 26) are obtained which characterized the stabilization of the cake during the transitional process of the regime according to the ratio of the shear forces, the mechanical and gravitational forces and the forces of the preponderant interactions of the surface.

$$
\begin{aligned}
V & =\left(-\left(\frac{\gamma Z M E S}{\mu \Delta P_{m}}\right) * \varphi\right) *\left(\frac{V}{t}\right)+\frac{\left(P_{a t m}+\Delta \Pi\right) v_{i}}{2 \Delta P_{m}} \\
\varphi & =\frac{45\left(x \lambda+d_{e}\right)}{150 \beta d_{e}+1,75 R_{e} d_{p}}
\end{aligned}
$$

$V=\left(\left(\frac{\gamma M_{c} S}{\Delta P_{m}}\right)\left(\frac{\alpha M_{c} S^{2} \beta-Z S}{\rho t}\right)\left(\frac{\varphi}{\Psi}\right)\right) *\left(\frac{t}{V}\right)+\frac{\left(P_{a t m}+\Delta \Pi\right) v_{i}}{2 \Delta P_{m}}$

$\mathrm{MFI}-\mathrm{DSP}=\frac{\varphi}{\Psi}\left(\left(\frac{M_{C} S}{Z \Delta P_{m}}\right)\left(\frac{\alpha M_{C} S^{2} \beta-Z S}{\rho}\right)\right)\left(\frac{\gamma}{t}\right)$

The studies conducted by Wang et al. and Xiao et al. showed that the MFI-DSP is proportional to the surface energy effect, to the cleavage effect, the fouling power, the mass of the pore blockage and is inversely proportional to the restructuring of the pseudo-membrane (Wang et al. 2012 and Xiao et al. 2013). The MFI-DSP can be determined experimentally by the fitting of the cumulative permeate volume against the inverse of the permeation rate. It allows to predict the reversible or the irreversible nature of the membrane fouling represent in Fig. 2 as well as the fouling power of the membrane and the fluid. Thus, the damage on the 
membrane and the loss of permeability can be better controlled to increase the membrane life and the process efficiency, (Wang et al. 2012).
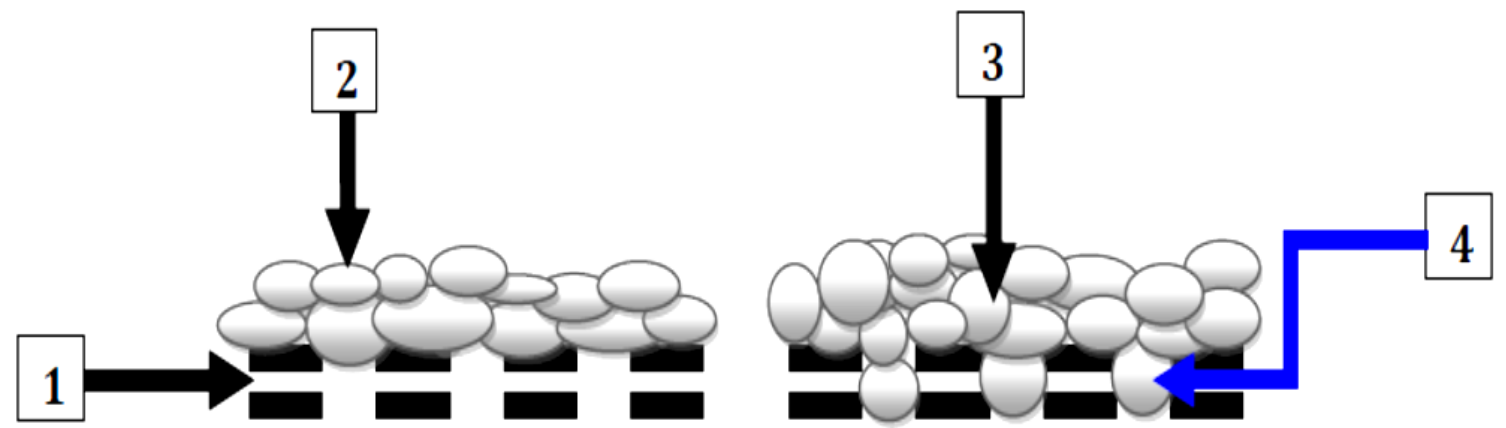

Figure 2: Mechanism of reversible and irreversible fouling process by cake formation in the membrane filtration surface predicted by MFI - DSP. (1) Porous membrane, (2) Incompressible cake, (3) Compressible cake and membrane pore blockage by obstruction and (4) Similarity of particle diameter and membrane pore diameter.

\section{8. $\quad$ Statistical analysis}

The validation of the new model constitutes the determining step in the modeling process. The procedure consists to plot the graph $1 / \mathrm{V}$ according to $1 / \mathrm{t}$ in order to present the evolution of the filtration process in the case of the pore blocking model obtained by the dynamic and phenomenological approach. Therefore, the optimization factors $\mathrm{m}$ and $\mathrm{n}$ are calculated according to the best correlation, the lowest error probability on the distribution function $\mathrm{F}$ and the lowest absolute relative error on the value calculated by the model below $5 \%$.

The phenomenological approach of the membrane fouling consists in the characterization of the various mechanisms predicted in the formulation of the model. Both approaches are combined in order to obtain a better optimization of the process and a better phenomenological description of the fouling process. The application of the new model and the MFI-DSP proposed in this study was performed on experimental data provided by Bouchard and Tamas 2004. Finally, the validation of the transitional model and of the MFIDSP focused on the analysis of the variance (ANOVA), the test of the critical information of Akaike AIC, the evaluation of the absolute relative errors and the probability of error on the distribution function, (Bassirou et al. 2017).

\section{Results and Discussion}

\subsection{Application of the new model and optimized filtration process}

A major limitation in using membrane industrial separation process is the loss of performance due to membrane fouling. According to the new proposed model, equation (18) appears to be 
the most appropriate to identify the membrane fouling mechanisms. Fig. 3 shows the filtration kinetics in five stages characteristic of the fouling process that allow to identify the pore blocking, the intermediate pore blocking, the complete pore blocking, the formation of the incompressible cake and the fouling compressible cake. Tables 1 and 2 indicate that the test results are statistically significant for the test of the fitting of the new model in a confidence interval CI of $95 \%$ with statistically insignificant distribution function error probabilities.

In addition, the optimization of the process by following the effect of the cake compress inside the pores and on the membrane surface shows that this compression is significant in the membrane fouling as demonstrated by the reduction of absolute relative error (RAE) and by the increase of the coefficient of the determination $\mathrm{R}^{2}$.

For all filtration modes, the membrane remains incompressible with regard to the compression of the cake under the action of the polarization of the gel layer, the mechanical forces, the surface forces, the decrease of the shear and the function of the cycles, in agreement with the related literature, (Bugge et al. 2012).

In the light of the obtained results, the comparative study of the new transitional proposed model with those of Hermia and Tien et al. showed a greater performance in the description of the dynamics and the phenomenology of the fouling process in terms of the number of characteristic parameters of the fouling and according to the regime transition against existing models that are limited to the description of the pore blocking (Hermia 1980; Tien et al. 2014). In the case of the filtration on cake, the values calculated from the new model are in close connection with those obtained by Schippers and Verdouw 1980. The results of the comparison test by the AIC index (Table 2) show that equation (18) is the most appropriate.
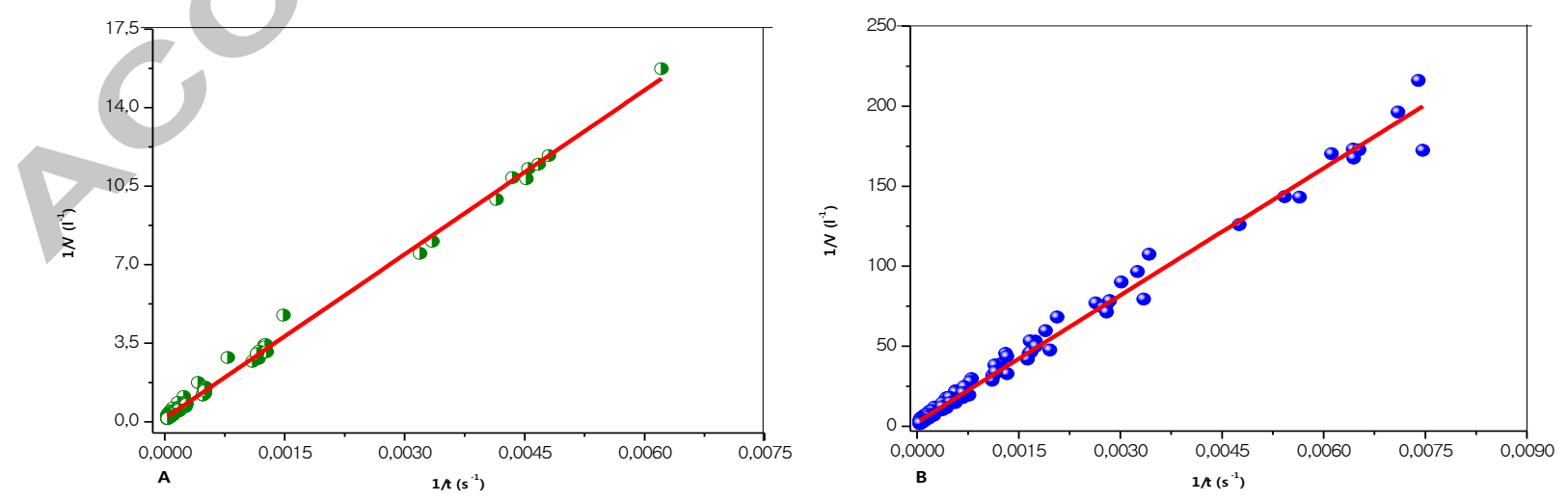

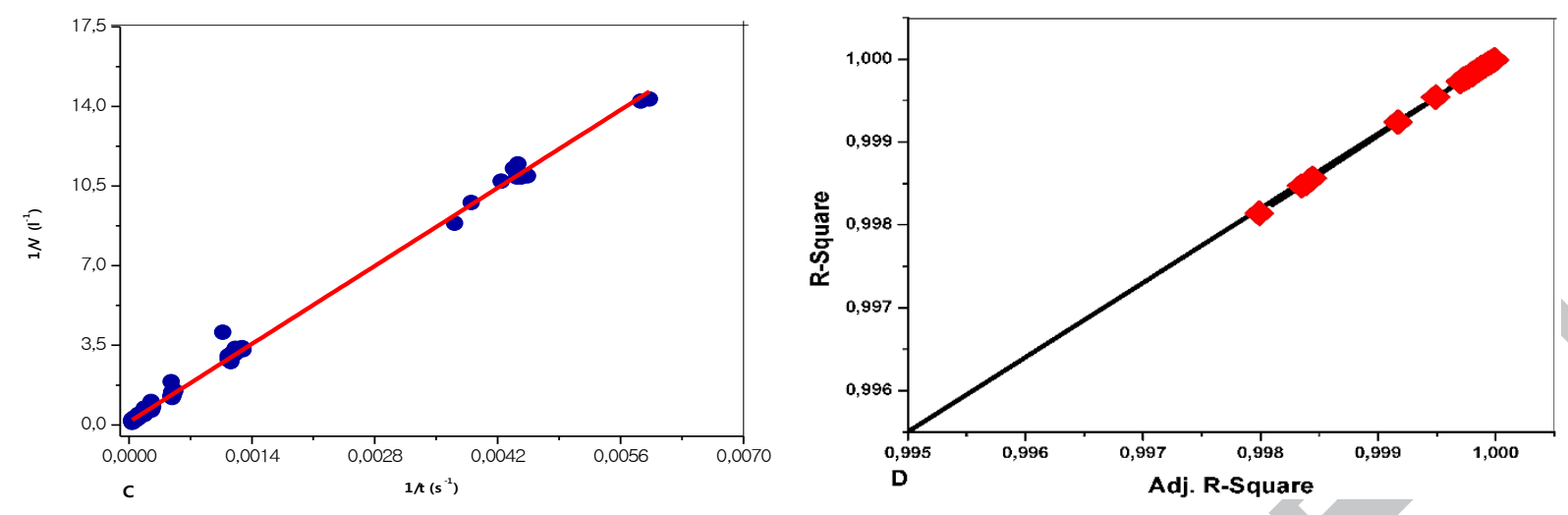

Figure 3: Experimental modeling values (A) all assay of UFT, (B) all assay of UFF, (C) all assay of NFT in polyethersulfone membrane of surface water filtration and (D) Evaluation of R-Square according Adj.R-Square from UFT, UFF and NFT. $\left(\mathrm{T}=25^{\circ} \mathrm{C} ; \mathrm{R}_{\mathrm{m}}=8.140 \times 10^{13} \mathrm{~m}^{-1} ; \Delta P_{m}=2 \times 10^{5} \mathrm{~Pa} ; \mathrm{U}_{\mathrm{t} / \mathrm{f}}=0.111 \mathrm{~m} \cdot \mathrm{s}^{-1} ; \mathrm{J}_{0}=3.5 \cdot 10^{-5} \mathrm{~m} . \mathrm{s}^{-}\right.$

$$
\left.{ }^{1} ; k_{p}=1.92 \times 10^{-10} \mathrm{~m} / \mathrm{s} . \mathrm{Pa} ; \mathrm{Q}=0.5 \mathrm{~L} / \mathrm{min}\right) \text {. }
$$

The results depicted in Fig. 3 (A, B and C) show that the standard pore blocking can be distinguished not only according to the configuration of the membrane module (frontal and tangential) but also according to the roughness, characterizing by the cut-off threshold of the membrane. The standard blocking in UFF is more persistent than in UFT and in NFT. It is a characteristic of adsorption inside pores as shown in Fig 3. Contrary to the work of Schippers and Verdouw; Hermia and Tien et al. (Schippers and Verdouw 1980, Hermia 1982 and Tien et al. 2014) the pore blocking is not fast with the membrane NF-270. It is particularly related to the nature of its porosity and also to the stability of its permeability compared to membranes PES-10 and UE-50.

As described by Tien et al. with the exception of the standard blocking, the intermediate blocking, the complete blocking and the cake formation are similarly characterized by a process of adsorption for the both modes and for all membranes types, (Tien et al. 2014). In spite of the perpendicular flow in UFF, the dynamic transition in cake formation follows the same mechanism as in the UFT and the NFT (Fig. 3).

The filtration on cake is much more intense in frontal mode where the accumulation and the polarization of the surface concentration of the fouling material are not subjected to the effect of the shear and / or to the roughness of the membrane. This favours more the membrane fouling by packing inside the pores and on the surface of the membrane. From fig. 3, in UFT and in NFT, the results show that the recirculation of the fluid has an effect of discontinuity on the mechanisms of the pore blocking contrarily to the frontal mode, (Haigang et al. 2016). The characterization of the membrane fouling by the effect of the configuration is totally in 
adequacy with the work of Hermia; Jaffrin et al. and Tien et al. (Hermia 1982, Jaffrin et al. 1997 and Tien et al. 2014).

It was demonstrated that the proposed model is effective in the prediction and the characterization of the membrane fouling process by blocking of pores with a very strong correlation of the predictive data, Fig. 3D. The new model globally characterizes the blocking of pores and the filtration on cake as described by Abdelrasoul et al. by considering the simultaneity of fouling phenomena, the association of fouling with particle size (cut of threshold) and the dynamics of the transmembrane flux (Abdelrasoul et al. 2013). The critical time corresponding to the jump of the transmembrane pressure is similar whatever the mode, the cut-off threshold and the nature of the filtration. The jump of the transmembrane pressure is characteristic of the incompressible and the compressible cake formation as described by Li et al. Haigang et al. Muthukumar et al. and Pradhan et al. (Haigang et al. 2016; Li et al. 2016a; Muthukumar et al. 2014, Pradhan et al. 2014).

The capacity of the new model to describe the transitional phenomenon in both tangential and frontal mode meets the objective of this modeling in the monitoring and the continuity of the process in order to predict the critical time corresponding to the complete blocking. The purpose of this prediction is to prevent the change of the permeate quality by infiltration through saturated membrane pores.

Table 1: Statistical analysis for the proposed model applied in UFT, UFF and NFT $\left(\mathrm{T}=25^{\circ} \mathrm{C} ; \mathrm{R}_{\mathrm{m}}=8.140 \times 10^{13}\right.$ $\left.\mathrm{m}^{-1} ; \Delta P_{m}=2 \times 10^{5} \mathrm{~Pa} ; \mathrm{U}_{\mathrm{t} / \mathrm{f}}=0.111 \mathrm{~m} \cdot \mathrm{s}^{-1} ; \mathrm{J}_{0}=3.5 \cdot 10^{-5} \mathrm{~m} \cdot \mathrm{s}^{-1} ; k_{p}=1.92 \times 10^{-10} \mathrm{~m} / \mathrm{s} . \mathrm{Pa} ; \mathrm{Q}=0.5 \mathrm{~L} / \mathrm{min}\right)$.

\begin{tabular}{|c|c|c|c|c|c|c|c|c|c|c|}
\hline & & & & ANOV & & & & & STATIST & \\
\hline & & & & & Model of Hern & and/or Tien & $a l$ & & & \\
\hline GLOB & $\overline{\mathrm{ASSAY}}$ & & DF & Sum of Squares & Mean Square & F Value & Prob $>F$ & R-Square & Adj. R-Square & Relative Error \\
\hline UFT & $1 / \mathrm{V}$ & Model & 1 & 965.5009 & 965.5009 & 28605.01986 & 0 & 0.9962 & 0.9962 & 0.0682 \\
\hline & $1 / \mathrm{V}$ & Error & 108 & 3.64531 & 0.03375 & & & & & \\
\hline UFF & $1 / \mathrm{V}$ & Model & 1 & 277227.2124 & 277227.2124 & 14986.0852 & 0 & 0.9906 & 0.9905 & 0.1022 \\
\hline & $1 / \mathrm{V}$ & Error & 133 & 2460.3636 & 18.4989 & & & & & \\
\hline NFT & $1 / \mathrm{V}$ & Model & 1 & 1318.8496 & 1318.8496 & 12136.1479 & 0 & 0.9888 & 0.9887 & 0.0623 \\
\hline & $1 / \mathrm{V}$ & Error & 130 & 14.1272 & 0.1087 & & & & & \\
\hline & & & & & New pr & osed model & & & & \\
\hline UFT & $1 / \mathrm{V}$ & Model & 3 & 1250.4425 & 416.8142 & 12548.6475 & 0 & 0.9963 & 0.9963 & 0.0474 \\
\hline & $1 / \mathrm{V}$ & Error & 107 & 3.5541 & 0.0332 & & & & & \\
\hline UFF & $1 / \mathrm{V}$ & Model & 3 & 400994.6356 & 133664.8785 & 7172.8557 & 0 & 0.9912 & 0.9911 & 0.0682 \\
\hline & $1 / \mathrm{V}$ & Error & 132 & 2459.7963 & 18.6348 & & & & & \\
\hline NFT & $1 / \mathrm{V}$ & Model & 3 & 1439.1750 & 479.7252 & 3912.6543 & 0 & 0.9884 & 0.9882 & 0.0348 \\
\hline & $1 / \mathrm{V}$ & Error & 107 & 13.1191 & 0.1226 & & & & & \\
\hline
\end{tabular}

Table 2: Statistical analysis of comparative model test UFT, UFF and NFT

$\left(\mathrm{T}=25^{\circ} \mathrm{C} ; \mathrm{R}_{\mathrm{m}}=8.140 \times 10^{13} \mathrm{~m}^{-1} ; \Delta P_{m}=2 \times 10^{5} \mathrm{~Pa} ; \mathrm{U}_{\mathrm{t} / \mathrm{f}}=0.111 \mathrm{~m} \cdot \mathrm{s}^{-1} ; \mathrm{J}_{0}=3.5 .10^{-5} \mathrm{~m} . \mathrm{s}^{-1} ; k_{p}=1.92 \times 10^{-10} \mathrm{~m} / \mathrm{s} \cdot \mathrm{Pa} ; \mathrm{Q}\right.$ $=0.5 \mathrm{~L} / \mathrm{min})$. 


\begin{tabular}{|c|c|c|c|c|c|c|}
\hline \multicolumn{7}{|c|}{ Akaike's Information Criterion Test (AIC) and Fitting test results } \\
\hline Assay & & RSS & $\mathrm{N}$ & Params & AIC & Akaike Weight \\
\hline \multirow[t]{2}{*}{ UFT } & Model * & 3.6453 & 110 & 2 & -368.5479 & 0.4191 \\
\hline & Model & 3.5535 & 110 & 3 & -369.2006 & 0.5809 \\
\hline \multirow[t]{2}{*}{ UFF } & Model * & 2619.1982 & 135 & 2 & 406.3221 & 0.0421 \\
\hline & Model & 2458.2851 & 135 & 3 & 400.0702 & 0.9579 \\
\hline \multirow[t]{2}{*}{ NFT } & Model * & 14.9574 & 132 & 2 & -281.4425 & 0.0023 \\
\hline & Model & 13.4029 & 132 & 3 & -293.6123 & 0.9977 \\
\hline Assay & $\mathrm{F}(\mathrm{IC}=\mathrm{C}$ & & Num & & Denom.DF & Prob $>F$ \\
\hline UFT & 8.6404 & & 1 & & 132 & 0.0039 \\
\hline UFF & 2.7658 & & 1 & & 107 & 0.0992 \\
\hline NFT & 14.9614 & & 1 & & 129 & $1.7322 \mathrm{E}-4$ \\
\hline \multicolumn{7}{|c|}{ Model $*=$ model of Hermia equations (1), Tien et al. equation (3), Schippers et Verdouw equation (5) and } \\
\hline \multicolumn{7}{|c|}{ Model = new model proposed equation (18) } \\
\hline
\end{tabular}

From Table 1, it is noted that the performance and the accuracy of the new model are characterized by the mean value of the compressibility factor and by the reduction of the absolute relative error. In UFT, $n=0.96$, REA $=[6.82 \%-4,74 \%]$. In UFF, $n=0.95$, REA $=$ $[10.22 \%-6.82 \%]$. In NFT, $n=0.97$, REA $=[6.23 \%-3.48 \%]$. From Fig.4D, it is noticed that whatever the mode, UFF, UFT or NFT, the optimization of the process according to the individual tests gives the following values for the reduction of the absolute relative error and the coefficient of determination: in UFF, $\operatorname{REA}_{\mathrm{UFF}}=[10.22 \%-2.42 \%]$ and $\mathrm{R}^{2}=0.999$ for $\mathrm{n}$ factor values between $[0.90-1.00]$; in, UFT, $\operatorname{REA}_{\mathrm{UFT}}=[6.82 \%-2.43 \%]$ and $\mathrm{R}^{2}=[0.999-1]$ for $n$-factor values between $[0.81-0.99]$; and in NFT, $\operatorname{REA}_{\mathrm{NFT}}=[10.22 \%-1.86 \%]$ and $\mathrm{R}^{2}=$ [0.999-1].

In short, the results of the monitoring of the effect of the cake compressibility and those of the optimized values of the permeation volume presented in Fig. 4 (A, B and C) indicate that an identification, essay by essay of the filtration, without distinction of the mode and the nature of the membrane, describes with more performance and efficiency the process of the regime transition. This is in perfect adequacy with the work of Bugge et al. (Bugge et al. 2012).
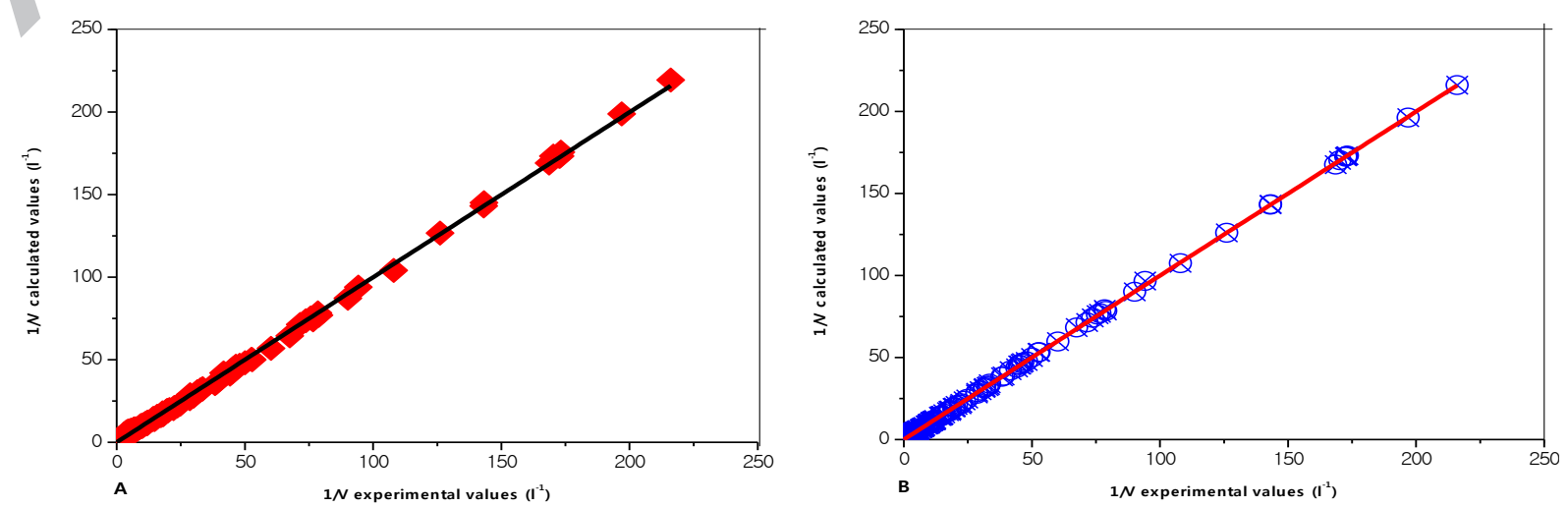

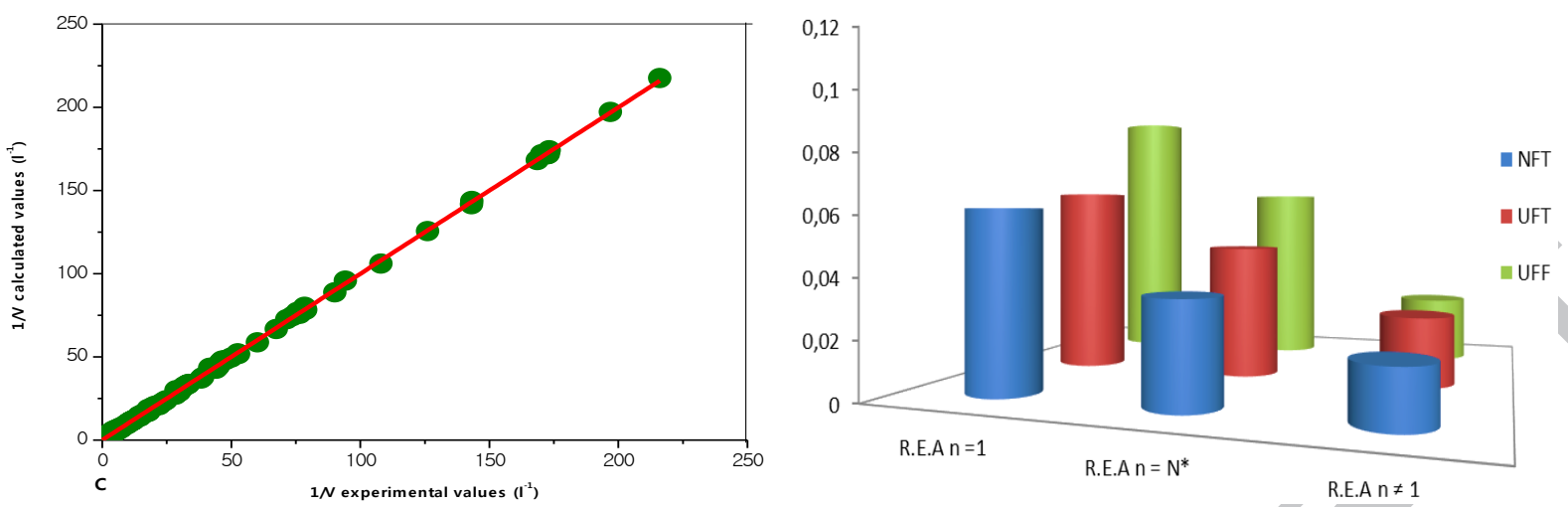

Figure 4: (A) $1 / \mathrm{V}$ calculated values (all Assay, $\mathrm{m}=\mathrm{n}=1$ ), (B) $1 / \mathrm{V}$ calculated values (all Assay, $\mathrm{m}=1 ; \mathrm{n}=$ $\mathrm{N}_{\text {average }}=0,96$ ), (C) $1 / \mathrm{V}$ calculated values (all Assay, $\mathrm{m}=1 ; \mathrm{n} \neq 1$ ) (UFT, UFF and NFT) according $1 / \mathrm{V}$ experimental values and (D) REA from UFF, UFT and NFT according " $n$ " factor of cake compressibility in surface water filtration in polyethersulfone membrane. $\left(\mathrm{T}=25^{\circ} \mathrm{C} ; \mathrm{R}_{\mathrm{m}}=8.140 \times 10^{13} \mathrm{~m}^{-1} ; \Delta P_{m}=2 \times 10^{5} \mathrm{~Pa} ; \mathrm{U}_{\mathrm{t} / \mathrm{f}}=\right.$ $\left.0.111 \mathrm{~m} . \mathrm{s}^{-1} ; \mathrm{J}_{0}=3.5 \cdot 10^{-5} \mathrm{~m} \cdot \mathrm{s}^{-1} ; k_{p}=1.92 \times 10^{-10} \mathrm{~m} / \mathrm{s} . \mathrm{Pa} ; \mathrm{Q}=0.5 \mathrm{~L} / \mathrm{min}\right)$.

\subsection{Prediction of the Fouling and its characterization}

\subsubsection{Fouling kinetics}

The results of the characterization of the membrane fouling kinetics showed partial orders between on the set of three types of filtration and on all the processed data, (Fig. 5), (Bessierea et al. 2005; Hermia 1982). The partial orders, experimentally determined show that membrane fouling is not homogeneous and follow a phenomenology of ascent of the fouling process according to its characteristic step until the jump of the critical transmembrane pressure, determining the regime transition towards the filtration on cake (Table 3 and Fig. 5). It is characterized by the attachment of the surface particles, by the adsorption inside the pores and on the surface of the membrane.

According to Daniel et al. and Tien et al., in a continuous system for $\mathrm{n}=[0-2]$, the cake fouling cannot be assimilated to a partial order of zero because it is tantamount to imposing a total cessation of filtration (Daniel et al. 2011 and Tien et al. 2014). However, the new proposed model allows a continuous filtration monitoring by regime transition. The kinetics of the predicted fouling process by the new model is similar to the results obtained by Daniel et al. and Tien et al. by admitting the continuity of the regime (Daniel et al. 2011 and Tien et al. 2014). The models proposed by these authors do not represent a continuous filtration, but only a discontinuous characterization of the filtration system (case of frontal mode); consequently, they do not allow to characterize a transitional system as shown in Table 3. The limit of the equation (27) when " $\omega$ " tends towards 4 , characterizes the appearance of the 
formation of the compressible cake, the nature and the level of the reversible or irreversible membrane fouling.

The establishment of the intermediate blocking, the complete blocking and the cake formation results from the accumulation of the material in the vicinity of the upper diameter of the pores (complete filling of the pores), as well as the accumulation in the vicinity of the filtering surface by interactions particles / particles and particles / membrane wall, according to Jianrong et al. and Xiang et al. (Jianrong et al. 2017 and Xiang et al. 2017). Indeed, the results represented in Table 3 corroborate the assumptions of the prediction and the characterization of the membrane fouling.

$$
\lim _{\omega \rightarrow 1}\left(\frac{\rho \mathrm{Z}^{2} \Psi}{\mu\left(\mathrm{ZS}-\alpha \mathrm{M}_{\mathrm{C}} \mathrm{S}^{2} \beta\right)}\right)\left(\frac{1}{\mathrm{t}}\right)^{\omega}
$$

Table 3: Kinetic partial orders of fouling mechanical characterization, $\left(\mathrm{T}=25^{\circ} \mathrm{C} ; \mathrm{R}_{\mathrm{m}}=8.140 \times 10^{13} \mathrm{~m}^{-1} ; \Delta P_{m}=\right.$ $\left.2 \times 10^{5} \mathrm{~Pa} ; \mathrm{U}_{\mathrm{t} / \mathrm{f}}=0.111 \mathrm{~m} \cdot \mathrm{s}^{-1} ; \mathrm{J}_{0}=3.5 \cdot 10^{-5} \mathrm{~m} \cdot \mathrm{s}^{-1} ; k_{p}=1.92 \times 10^{-10} \mathrm{~m} / \mathrm{s} . \mathrm{Pa} ; \mathrm{Q}=0.5 \mathrm{~L} / \mathrm{min}\right)$.

\begin{tabular}{lccc}
\hline & \multicolumn{3}{c}{ UFT - UFF - NFT } \\
\cline { 2 - 4 } Fouling mechanicals & $\begin{array}{c}\text { Kew } \\
\text { Model } \boldsymbol{\omega}\end{array}$ & $\begin{array}{c}\text { Kodel of Tien et al. and Daniel et } \\
\text { Modials orders }\end{array}$ & $\begin{array}{c}\text { Standard Error } \\
\mathbf{a} \boldsymbol{\omega}\end{array}$ \\
Cake filtration & 3.7623 & 0.00 & 0.0749 \\
Complete blocking pores & 2.8766 & 2.00 & 0.0595 \\
Intermediate blocking pores & 1.9421 & 1.00 & 0.0513 \\
Standard blocking pores & 1.0262 & 1.50 & 0.0598 \\
\hline
\end{tabular}
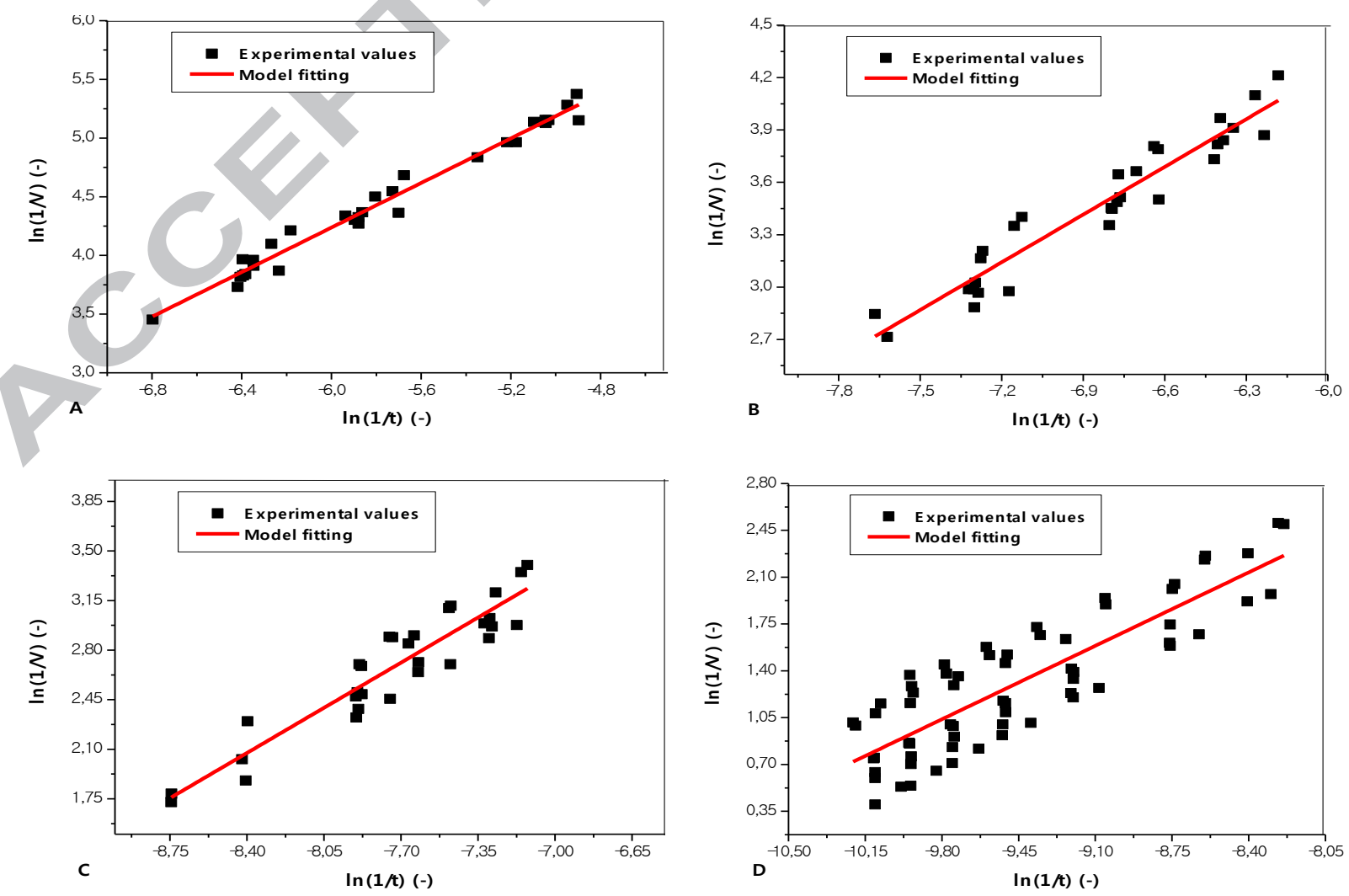
Figure 5: Experimental results of the new model application in the fouling process stage characterization. (A) Pores standard blocking, (B) Intermediate Pores blocking, (C) Complete Pores blocking and (D) Cake filtration (incompressible and compressible cake) for all assay. $\left(\mathrm{T}=25^{\circ} \mathrm{C} ; \mathrm{R}_{\mathrm{m}}=8.140 \times 10^{13} \mathrm{~m}^{-1} ; \Delta P_{m}=2 \times 10^{5} \mathrm{~Pa} ; \mathrm{U}_{\mathrm{t} / \mathrm{f}}=\right.$ $\left.0.111 \mathrm{~m} . \mathrm{s}^{-1} ; \mathrm{J}_{0}=3.5 .10^{-5} \mathrm{~m} . \mathrm{s}^{-1} ; k_{p}=1.92 \times 10^{-10} \mathrm{~m} / \mathrm{s} . \mathrm{Pa} ; \mathrm{Q}=0.5 \mathrm{~L} / \mathrm{min}\right)$.

\subsubsection{Prediction of the mass of the cake}

The results of the predictive study of the accumulation of the fouling material (Fig. 6) indicate that the irreversible fouling caused by the loss of the permeability, can be determined according to the shear factor $\beta$ and the mass of the cake $M_{c}$ using equation (20). The experiments conducted by Bouchard and Tamas 2004, whose data were used in this study, provided a loss of permeability of $24 \%$ for the membrane PES-10, $21 \%$ for the membrane NF-270 and $40-60 \%$ for the membrane EU-50.

The monitoring of the evolution of the shear factor $\beta$ and the mass of the cake $\mathrm{M}_{\mathrm{c}}$ correlates well with the experimental results on the loss of permeability and confirms the predictive description of the transitional fouling process by the new model. The frontal filtration generates an important mass of the cake compared to the tangential filtration, due respectively to a unidirectional permeation flow and a very weak shearing effect on the accumulation of the material forming the cake. This massive deposit of particles results from the absence of recirculation and from the effect of the settlement of the mass on the membrane surface. A linear balance, characteristic of the transition phenomenon in the fouling process is then established, in which the process of pores blocking according to the restructuring of the pseudo-membrane factor by the action of settlement favours an important adsorption inside the pores.

From fig. 6, the results showed that the membrane fouling dynamics in frontal mode is reduced only to the effect of the settlement of the cake mass contrarily to the tangential mode in which the fouling process is subjected to the dynamics of the pore blockage and to the transition process towards the filtration on cake. The predictive evolution of the cake mass and the thickness is in perfect correlation with the prediction of the membrane fouling by MFI - DSP. It is characterized by the multiple interaction forces with respect to the mechanical forces and depending on the mode of filtration. Fig. 6 (A, B, C and D) shows that the amount of the fouling material describes a transitional fouling process by pores blocking, incompressible cake and compressible cake according to the rate of permeation with a progressive loss of the permeability with time.

These three characteristic phases of the fouling coupled with the evolution of the shear factor (Figs. 6A and 6C) allowed to identify the critical mass of the irreversible membrane fouling. 
Moreover, the increase of the mass results from the effect of the cut-off threshold of the membrane, namely 300Da, $10 \mathrm{kDa}$ and $100 \mathrm{kDa}$ for NFT, UFT and UFF respectively. Indeed, as it was observed by $\mathrm{He}$ et al. and Jianrong et al. more the cut-off threshold is important more the roughness of the membrane is important, (He et al. 2005; Jianrong et al. 2017). This rough morphology allows the attachment of the materials responsible of the membrane fouling (Xiang et al. 2018).

Fig. 6A indicates that the compression of the cake mass described by the new model is due to the effect of the shear and the recirculation factor under the action of the mechanical forces according to the time of permeation; it considerably affects the fouling dynamics and subsequently the phenomenology of the process. The results of the fig. 6 (B and C) show that according to the mass of the cake, the transition of the fouling is due to a resistance induced by the effect of the osmotic pressure and by the resistance of the incompressible cake; this leads to an irreversible fouling mainly in the case of the membrane EU-50 (Li-guo et al. 2015). This is in good agreement with the prediction of the transitional fouling by the new proposed model and the new modified fouling index (MFI - DSP).
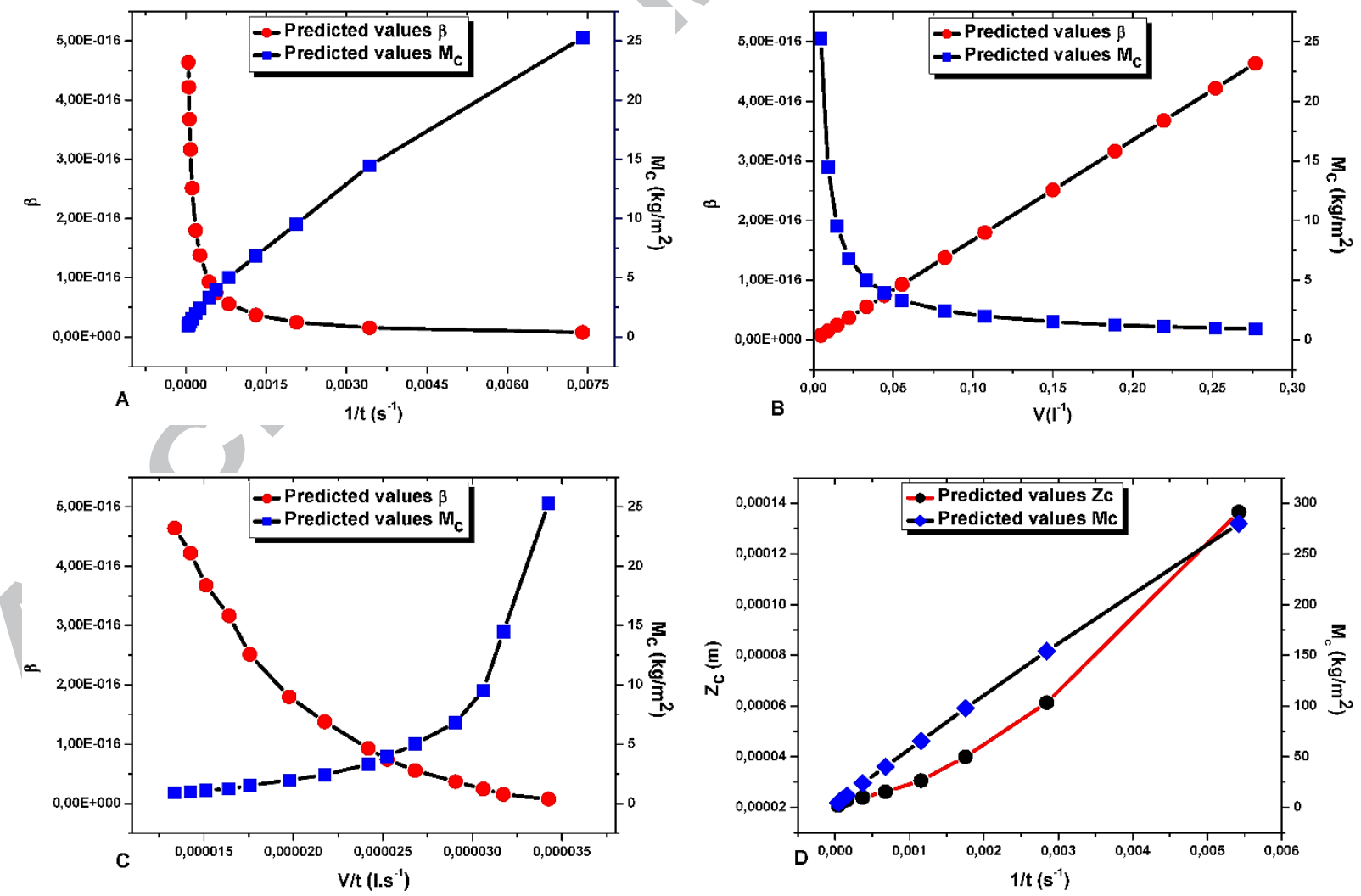

Figure 6: Cake matter, Cake thickness and Shear factor in polyethersulfone membrane in surface water filtration. (A) $M_{c}=\mathbf{f}(\mathbf{1} / \mathbf{t}), \boldsymbol{\beta}=\mathbf{f}(\mathbf{1} / \mathbf{t}),(B) M_{c}=\mathbf{f}(V), \beta=f(V),(C) M_{c}=f(V / t), \beta=f(V / t)$ and $Z_{c}=f(1 / t)$, 


$$
\begin{gathered}
\left(\mathrm{T}=25^{\circ} \mathrm{C} ; \mathrm{R}_{\mathrm{m}}=8.140 \times 10^{13} \mathrm{~m}^{-1} ; \Delta P_{m}=2 \times 10^{5} \mathrm{~Pa} ; \mathrm{U}_{\mathrm{t} / \mathrm{f}}=0.111 \mathrm{~m} \cdot \mathrm{s}^{-1} ; \mathrm{J}_{0}=3.5 .10^{-5} \mathrm{~m} \cdot \mathrm{s}^{-1} ; k_{p}=1.92 \times 10^{-10} \mathrm{~m} / \mathrm{s} . \mathrm{Pa} ; \mathrm{Q}\right. \\
\left.=0.5 \mathrm{~L} / \mathrm{min} ; \alpha=2.5 \times 10^{12} \mathrm{~m} / \mathrm{kg}, \mathrm{Z}_{\mathrm{m}}=200 \mu \mathrm{m}\right) .
\end{gathered}
$$

\subsection{Modified fouling index - Dynamical surface phenomena (MFI - DSP)}

The membrane fouling in tangential mode is characterized by a break of the force balance during the passage of the blocking of the pores towards the cake filtration by incompressible cake process. This effect favours an important permeation (Fig. 7A and 7C) compared to the frontal mode (Fig. 7B) where the shear is practically insignificant. The membrane UE-50 in UFF presents a level of fouling characteristic of a perpendicular flow exhibiting non-dynamic fouling with three levels of rupture of the linear balance of the force ratios.

Fig. 7B shows that the effect of compaction of the cake without shear is the consequence of low permeation volumes where the transition of the fouling is static. At this level, the MFI DSP $\left(\mathrm{R}^{2}=0.99\right)$ reveals that the loss of linearity of the force ratios is a function of the effect of settlement. The compressible cake is limited according to the permeation volume. The incompressible cake is again setup characterizing an irreversible fouling of the membrane by an induced resistance, (Bassirou et al. 2017; Bacchin et al. 2011; Tien et al. 2014; Pradhan et al. 2014). This irreversible fouling is correlated by the results of the study of the kinetics of the fouling and those of the validation of the new transitional model. The second incompressible cake provoked a loss of permeability of the membrane UE - 50 of $40-60 \%$ during the tests, (Bouchard and Tamas 2004).

The application of the MFI-DSP in tangential mode shows that the transition of the fouling for the membrane NF-270 (Fig. 7C, $\mathrm{R}^{2}=0.991$ ) is fast and the balance of the incompressible cake is maintained at the maximum permeation. Furthermore, it is stabilized by the balance of the ratios between the multiple interaction forces and the mechanical forces according to the shear and the recirculation factor. According to the nature of the membrane NF - 270, the MFI - DSP reveals that the smoothing of this membrane and the effect of the nominal diameter of its pores are the main characteristic factors of the fast blocking of pores and the persistence of the incompressible cake, (Bacchin et al. 2011; Tien et al. 2014).

Experimental tests revealed that the characterization of the nature of the fouling for this type of membrane is in perfect adequacy with the level of loss of permeability of $21 \%$ maximum, (Bouchard and Tamas 2004). In addition, the MFI - DSP shows that the effect of the induction of the osmotic pressure is greater in nanofiltration than in the other cases by the stabilization of the incompressible cake. The latter took place under the influence of the shear and the 
delay in the implementation of the compressible cake for a maximum permeation volume, $\mathrm{V}$ $=8 \mathrm{~L}$, (Fig. 7C) as described in the work of Bassirou et al. and Haigang et al. (Bassirou et al. 2017; Haigang et al. 2016).

The results of the MFI - DSP on the membrane PES - 10 indicate that the blocking of pores is a characteristic fouling of this membrane for a permeation volume, $\mathrm{V} \approx 6 \mathrm{~L}$. The mechanism of the transitional dynamic fouling identified by the MFI - DSP on the membrane PES-10 is mainly influenced by the effect of the adsorption process inside the pores and also by the sequestration of the fouling particles under the effects of the surface energy and the balance of power ratios as described by $\mathrm{Wu}$ et al.,; Robles et al., and Zhang and Ding (Robles et al. 2013; Zhang and Ding 2015; Wu et al. 2011).

Fig. 7A shows that from the rupture of the forces balance, expressed by the ratio between the fouling power and the restructuring factor of the pseudo-membrane, there is the formation of a very ephemeral incompressible cake. This is due to the effect of the shear and the recirculation factor which strongly affect the stability of the cake, leading to the transition of the regime towards a compressible cake.

This transition confirmed by Fig. 7C $\left(R^{2}=0.992\right)$ is the consequence of the roughness (Xiang et al. 2018), the nominal diameter of the membrane PES-10 and the inductive effect of the osmotic pressure during the fouling, having provoked a permeability loss of $24 \%$ maximum, Bouchard and Tamas 2004. Indeed, the results of the evaluation of the MFI - DSP showed that the new modified fouling index is an efficient and effective parameter in the identification and the characterization of the mechanisms of the membrane fouling process in tangential and in frontal filtration mode.
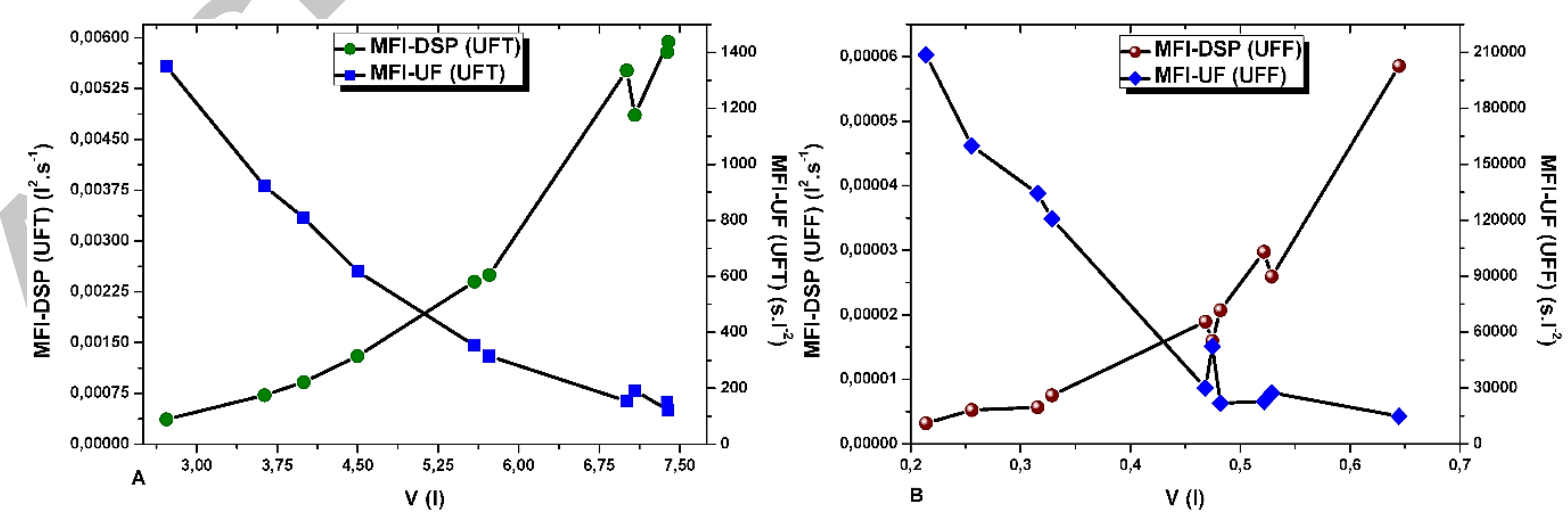


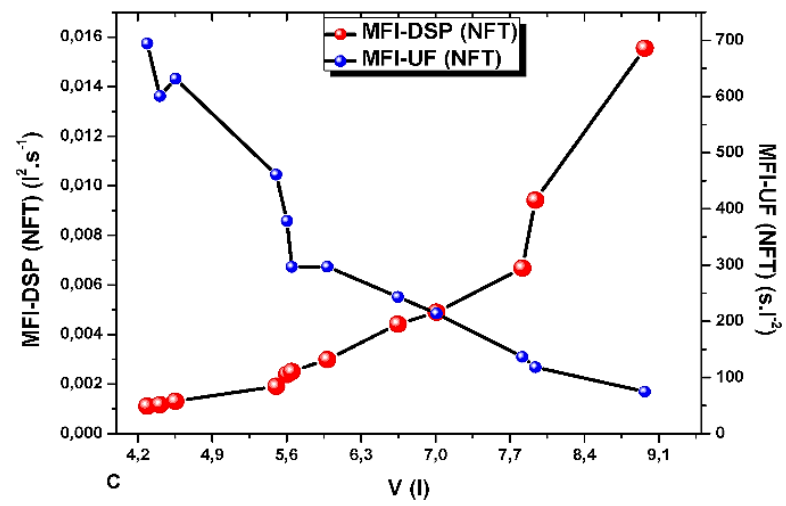

Figure 7: MFI - DSP evaluation according to the permute volume, (A) in UFT, (B) in UFF and (C) in NFT, in polyethersulfone membrane of surface water filtration. $\left(\mathrm{T}=25^{\circ} \mathrm{C} ; \mathrm{R}_{\mathrm{m}}=8.140 \times 10^{13} \mathrm{~m}^{-1} ; \Delta P_{m}=2 \times 10^{5} \mathrm{~Pa} ; \mathrm{U}_{\mathrm{t} / \mathrm{f}}=\right.$ $\left.0.111 \mathrm{~m} . \mathrm{s}^{-1} ; \mathrm{J}_{0}=3.5 \cdot 10^{-5} \mathrm{~m} \cdot \mathrm{s}^{-1} ; k_{p}=1.92 \times 10^{-10} \mathrm{~m} / \mathrm{s} . \mathrm{Pa} ; \mathrm{Q}=0.5 \mathrm{~L} / \mathrm{min}\right)$.

\section{Conclusions}

In membrane filtration, flux decline is a result of the increase in the membrane resistance by the membrane pore blockage and the formation of a cake layer on the membrane surface. The pore blocking increases the membrane resistance while the cake formation creates an additional layer of resistance to the permeate flow. Pore blocking and cake formation can be considered as two essential mechanisms for membrane fouling. The study of the modeling of the process of transitional membranes fouling using two coupled approaches, allowed to formulate a new optimized model by taking into consideration the significant effect of the compressibility of the cake fouling in the continuous systems. The results obtained allowed to identify the nature and the type of the fouling using new parameters. The new modified fouling index MFI-DSP and the study of kinetics engendered a significant contribution in the elucidation of the complexity of the mechanisms of membrane fouling in order to determine the best solutions for the antifouling of membranes. In the aim to generalize the laws resulting from this study, the new optimized model was validated on experimental data in frontal and in tangential filtration.

From now, it will be possible to elucidate the nature and the type of the membrane fouling occurring during the filtration cycles by the new proposed model and the news parameters characterizing membrane fouling. Indeed, the mechanism of the membrane pressure jump under the action of the ratio of the mechanical forces, the multiple interaction forces, the pseudo-membrane restructuring factor and the effect of the shearing factor allowed to characterize the irreversible membrane fouling by a critical flux of permeation above of which, no volume of permeate can be observed; consequently, it affects negatively the performance of the filtration process. The results of the assessment of transitional blockage by 
MFI - DSP demonstrated with accuracy the nature and the level of the fouling for each type of membrane. The identification of the transitional process of the fouling by MFI-DSP is related to the balance of the multiple interaction forces represented by the fouling power, the surface energy, the mechanical forces representing the effect of the jump of the transmembrane pressure and by the inductive effect of the osmotic pressure. Indeed, the established fouling process model effectively explains the various stages of transitional fouling which remains not understood in the process of the modeling of the fouling in membrane filtration. According to the result obtained, the chemical particle attachment mechanisms are based on the heterogeneous properties of the interacting surfaces, and thus can be characterized using some global parameters, such as: surface energy, fouling power and restructuration factor of pseudo-membrane. At last, different parts of the surface have different affinities to the membrane. The membrane surface, especially that modified, also likely has heterogeneous surface properties relevant to foulant attachment. This heterogeneity can be attributed to different physical and/or chemical origins.

\section{ACKNOWLEDGEMENTS}

The authors gratefully acknowledge the team of biomaterials and transport phenomena Laboratory (LBMPT) and the University of Medea.

\section{INTEREST CONFLICT}

The authors declare that there is no conflict of interests.

\section{Nomenclature}

$d_{p}$, (m) pore diameter,

$I,\left(\mathrm{~m}^{-2}\right)$ a Schippers modified fouling index,

$J_{p 0},(\mathrm{~m} / \mathrm{s})$ initial flow,

$J_{p c},(\mathrm{~m} / \mathrm{s})$ permeate flow,

$k$, constant of Hermia equation (1),

$k_{p}$, membrane permeability (m/Pa.s)

$K_{s}\left(\mathrm{~m}^{-3}\right)$ fouling characterize constant,

MES, $\left(\mathrm{kg} / \mathrm{m}^{3}\right)$ suspension matter,

$\mathrm{M}_{\mathrm{c}}\left(\mathrm{kg} / \mathrm{m}^{2}\right)$ cake mass,

$m$ (-) factor of membrane incompressibility,

$n$, constant of Hermia equation (1),

$n$ (-) factor cake compressibility,

$N\left(\mathrm{~m}^{-2}\right)$ pore number of surface membrane unit,

$Q,(\mathrm{~L} / \mathrm{min})$ fluid flow supply, 
$Q_{p}\left(\mathrm{~m}^{3} / \mathrm{s}\right)$ filtered volume flow,

$Q_{p 0}\left(\mathrm{~m}^{3} / \mathrm{s}\right)$ initial filtered volume flow,

$R_{m},\left(\mathrm{~m}^{-1}\right)$ membrane resistance,

$R_{c},\left(\mathrm{~m}^{-1}\right)$ cake resistance,

$\mathrm{S},\left(\mathrm{m}^{2}\right)$ membrane surface,

$t$, (s) filtered time,

$U_{t},\left(\mathrm{~m} . \mathrm{s}^{-1}\right)$ tangential velocity,

$\mathrm{U},(\mathrm{m} / \mathrm{s})$ crossflow velocity,

$V,\left(\mathrm{~m}^{3}\right)$ cumulative filtered volume,

$V_{S}\left(\mathrm{~m}^{3} \cdot \mathrm{m}^{-2}\right)$ specific Volume,

$v_{i},\left(\mathrm{~m}^{3}\right)$ elementary filtered volume,

$\mathrm{Z}_{\mathrm{c}}(\mathrm{m})$ cake thickness,

$Z_{m}(\mathrm{~m})$ effective membrane thickness,

$\mathrm{Z}$, (m) global thickness,

\section{Greck Letters}

$\alpha(\mathrm{m} / \mathrm{kg})$ hydraulic cake resistance,

$\beta(-)$ dimensionless shear factor equation,

$\beta$ (-) dimensionless parameter of filtered fluid,

$\beta_{2}(-)$ constant of Chi Tien and al., (2014),

$\Delta P_{m},(\mathrm{~Pa})$, , transmembrane pressure,

$\Delta \pi,(\mathrm{kPa})$ osmotic pressure,

$\gamma(\mathrm{N} / \mathrm{m})$, surface global energy,

$\mu_{i}\left(\mathrm{~J} . \mathrm{mol}^{-1}\right)$, chemical potential,

$\mu$ (Pa.s), dynamical fluid viscosity,

$\Psi(-)$ pseudo-membrane restructuring factor,

$\varphi,(-)$ fouling power,

$\Phi(-)$ fluid recirculation factor,

$\varepsilon(-)$, membrane porosity,

$\rho\left(\mathrm{kg} / \mathrm{m}^{3}\right)$ fluid density,

$\tau(-)$, crookedness factor

\section{Acronyms}

\section{AIC, Akaike's Information Criterion Test}

CFS - MFI, crossflow sampler modified fouling index,

$\mathrm{MFI}_{0,45}$, modified fouling index for membrane diameter 0,45 $\mu \mathrm{m}$,

MFI - UF, modified fouling index - tangential ultrafiltration,

MFI - DSP, modified fouling index - dynamical surface phenomena,

NFT, tangential nanofiltration,

R.E.A, Absolute Relative Error,

UFT, tangential ultrafiltration,

UFF frontal ultrafiltration, 


\section{References}

Albasi Claire, C., Jauregui, H., Ulises, J., Magnet, A., Schetrite, S., Zarragoitia-González, A., 2007. Modélisation et simulation dynamique du traitement des effluents par bioréacteurs à membranes immergées. In: $11^{\text {ème }}$ Congrès de la Société Française de Génie des Procédés, 9-11 Octobre 2007, Saint-Etienne, France.

Abdelrasoul, A., Doan, H., Lohi, A, 2013. A mechanistic model for ultrafiltration membrane fouling by latex. Journal of Membrane Science 433, 88-99.

Arukalam, I.O., Oguzie, E.E., Li, Y, 2016. Fabrication of FDTS-modified PDMS-ZnO nanocomposite hydrophobic coating with anti-fouling capability for corrosion protection of Q235 steel. Journal Colloid Interface Science 484, $220-28$.

Bassirou, M.H., Benkortbi, O., Hamadache, M., Hanini, S., Amrane, A, 2017. New approach of the fouling process modeling in tangential filtration on cake, Desalination and Water Treatment, 74, 71-86.

Bessierea, Y., Abidine, N., Bacchin, P, 2005. Low fouling conditions in dead-end filtration: Evidence for a critical filtered volume and interpretation using critical osmotic pressure. Journal of Membrane Science 264, 3747.

Bacchin, P., Mart, A., Duru, P., Meireles, M., Aimar, P, 2011. Colloidal surface interactions and membrane fouling. Investigations at pore scale. Advances in Colloid and Interface Science 164, 2-11.

Boerlage, S.F.E., Kennedy, M.D., Aniye, M.P., Abogrean, E.M., El-Hodali, D.E.Y., Tarawneh, Z.S., Schippers, J.C, 2000. Modified fouling index-UF to compare pre-treatment processes of reverse osmosis feed water. Procedeengs of the Conference on Membranes in Drinking and Industrial Water Production 1, 397-10.

Boerlage, S.F.E., Kennedy, M.D., Dickson, M.R., El-Hodali, D.E.Y., Schippers, J.C, 2002. The modified fouling index using ultrafiltration membranes (MFI-UF): characterisation, filtration mechanism and proposed reference membrane. Journal of Membrane Sciences 197, 1-21.

Bouchard, C., Tamas, A.P, 2004. Etude comparée du colmatage en nano-filtration et en ultrafiltration d'eau de surface. Laval University Canada, www.Thesis.ulaval.ca/ 22074, 150-85.

Bugge, T.V., Jørgensen, M.K., Christensen, M.L., Keiding, K, 2012. Modeling cake buildup under TMP-step filtration in a membrane bioreactor: Cake compressibility is significant. Water Research 46, 4330 - 38.

Comiti, J., Renaud, M., 1989. A new model for determining mean structure parameters of fixed beds from pressure drop measurements: application to beds packed with parallelepipedal particles. Chemical Engineering Science 44, 1539 - 45 .

Daniel, R.C., Billing, J.M., Russell, R.L., Shimskey, R.W., Smith, H.D., Peterson, R.A, 2011. Integrated pore blockage-cake filtration model for crossflow filtration. Chemical Engineering Research and Design 89, $1094-03$.

Ergun, S, 1952. Fluid flow through packed columns. Chemical Engineering Progress 48, 89-94.

Hermia, J, 1982. Constant pressure blocking filtration laws -application to power-law non-Newtonian fluids. Institute of Chemical Engineering 60, 183-87.

Huang, X., Wei, C.H., Yu, K.C, 2008. Mechanism of membrane fouling control by suspended carriersin a submerged membrane bioreactor. Journal of Membrane Science 309, 7-16.

Huang, H., Young, T., Jacangelo, J.G, 2009. Novel approach for the analysis of bench-scale, low-pressure membrane fouling in water treatment. Journal of Membrane Science 334, 1-8.

Han, Q., Li, W.Y., Trinh, T.A., Liu, X., Chew, J.W, 2017. A network-based approach to interpreting pore blockage and cake filtration during membrane fouling. Journal of Membrane Science 528, 112-25.

Huang, H., Young, T.A., Jacangelo, J.G., 2008. Unified membrane fouling index for low pressure membrane filtration of natural waters: principles and methodology. Environment Science and Technology 42, $714-20$. 
He, Y., Xu, P., Li, C., Zhang, B, 2005. High-concentration food wastewater treatment by an anaerobic membrane bioreactor. Water Research 39, 4110 - 18.

Haigang, L., Xia, L. H., Mei, Y, 2016. Modeling organic fouling of reverse osmosis membrane: From adsorption to fouling layer formation. Desalination 386, 25-31.

Koo, C.H., Mohammad, A., Suja, F., 2014. Correlation between modified fouling index (MFI) and crossflow sampler-modified fouling index (CFS-MFI) under constant flux filtration. Journal of Water Process Engineering 3, 151-54.

Jaffrin, M.Y., Ding, L.H., Couvreur, C., Khari, P, 1997. Effect of ethanol on ultrafiltration of bovine albumin solutions with organic membranes. Journal of Membrane Science 124, 233 - 41.

Javeed, M.A., Chinu, K., Shon, H.K., Vigneswaran, S., 2009. Effect of pre-treatment on fouling propensity of feed as depicted by the modified fouling index (MFI) and cross-flow sampler-modified fouling index (CFSMFI). Desalination 238, 98-08.

Jin, Y., Ju, Y., Lee, H., Hong, S, 2015. Fouling potential evaluation by cake fouling index: Theoretical development, measurements, and its implications for fouling mechanisms. Journal of Membrane Science 490, 57-64.

Ju, Y., Hong, I., Hong, S, 2015. Multiple MFI measurements for the evaluation of organic fouling in SWRO desalination. Desalination 365, 136-43.

Jin, Y., Lee, H., Jin, Y.O., Hong, S, 2017. Application of multiple modified fouling index (MFI) measurements at full-scale SWRO plant. Desalination 407, 24-32.

Jee, K.Y., Shin, D.H., Lee, Y.T, 2016. Surface modification of polyamide RO membrane for improved fouling resistance. Desalination 394, 131-37.

Jianrong, C., Hongjun, L., Liguo, S., Yiming, H., Meijia Z., Bao-Qiang, Liao, 2017. Realization of quantifying interfacial interactions between a randomly rough membrane surface and a foulant particle. Bioresource Technology 226, $220-28$.

Li, N., Zhang, J., Tian, Y., Zhang, J., Zhan, W., Zhao, J., Ding, Y., Zuo, W, 2016a. Hydrophilic modification of polyvinylidene fluoride membranes by $\mathrm{ZnO}$ atomic layer deposition using nitrogen dioxide/diethyl zinc functionalization. Journal of Membrane Science 514, 241-49.

Li, N., Zhang, J., Tian, Y., Zhao, J., Zhang, J., Zuo, W, 2016b. Anti-fouling potential evaluation of PVDF membranes modified with $\mathrm{ZnO}$ against polysaccharide. Chemical Engineering Journal 304, 165-74.

Li-guo, S., Qian, L., Jian-Rong, C., Hua-Chang, H., Yi-Ming, H., Hong-Jun, L, 2015. Membrane fouling in a submerged membrane bioreactor: Impacts of floc size. Chemical Engineering Journal 269, 328 - 34.

Lodge, B.N., Judd, S.J., Smith, A.J, 2004. Characterization of dead-end ultrafiltration of biotreated domestic wastewater. Journal of Membrane Science 231, 91-98.

Muthukumar, S., Anupam, S., Anurag, S.R, 2014. Modeling of Filtration Processes-Microfiltration and Depth Filtration for Harvest of a Therapeutic Protein Expressed in Pichia pastoris at Constant Pressure. Bioengineering $1,260-77$.

Maximous, N., Nakhla, G., Wong, K., Wan, W, 2010. Optimization of $\mathrm{Al}_{2} \mathrm{O}_{3} / \mathrm{PES}$ membranes for wastewater filtration. Separation and Purification Technology 73, $294-01$.

Marselina, Y., Le-Clech, L.P., Stuetz, R.M., Chen, V, 2009. Characterization of membrane fouling deposition and removal by direct observation technique. Journal of Membrane Science 341, 163-71.

Mondal, S., De, S, 2010. A fouling model for steady state crossflow membrane filtration considering sequential intermediate pore blocking and cake formation. Separation and Purification Technology 75, 222-28.

Meijia, Z., Huachang, H., Hongjun, L., Liguo, S., Haiying, Y., Guangcai, M., Jianrong, C., Bao-Qiang, L, 2018. Mechanistic insights into alginate fouling caused by calcium ions based on terahertz time-domain spectra analyses and DFT calculations. Water Research 129, 337 - 46. 
Paipuri, M., Kim, S.H., Hassan, O., Hilal, N., Morgan, K, 2015. Numerical modelling of concentration polarisation and cake formation in membrane filtration processes. Desalination $365,151-59$.

Pradhan, M., Vigneswaran, S., Ben Aim, R., Kandasamy, J, 2014. Modelling of particle deposition in a submerged membrane microfiltration system. Desalination 350, 14-20.

Robles, A., Ruano, M.V., Ribes, J., Seco, A., Ferrer, J, 2013. A filtration model applied to submerged anaerobic MBRs (SAnMBRs). Journal of Membrane Science 444, 139-47.

Salinas-Rodriguez, S.G., Amy, G.L., Schippers, J.C., Kenned, M. D., 2015. The Modified Fouling Index Ultrafiltration constant flux for assessing particulate/colloidal fouling of RO systems. Desalination 365, 79-91.

Schippers, J.C., Verdouw, J, 1980. The modified fouling index, a method of determining the fouling characteristics of water. Desalination 32, 137-48.

Tien, C., Ramarao, B.V., Yasarla, R, 2014. A blocking model of membrane filtration. Chemical Engineering Science $111,421-31$.

Tien, C., Ramarao, B.V, 2013. On analysis and modeling of cross-flow membrane filtration of particle suspensions. Chemical Engineering 2, 245-54.

Wu, J., He, C., Jiang, X., Zhang, M, 2011. Modeling of the submerged membrane bioreactor fouling by the combined pore constriction, pore blockage and cake formation mechanisms. Desalination 279, 127-34.

Wang, X.M., Li, X.Y, 2012. Unified model for quantification of concentration polarization (CP) of particles during cross-flow membrane filtration. Colloids and Surfaces A: Physicochemical Engineering Aspects 407, 9907.

Xiao, K., Shen, Y., Huang, X, 2013. An analytical model for membrane fouling evolution associated with gel layer growth during constant pressure stirred dead-end filtration. Journal of Membrane Science 427, 139-49.

Xiang, C., Meijia, Z., Lining, Y., Hongjun, L., Xilin, W., Yiming, H., Liguo, S, 2017. Quantification of interfacial interactions between a rough sludge floc and membrane surface in a membrane bioreactor. Journal of Colloid and Interface Science 490, 710 - 18.

Xiaolu, Q., Xiang, C., Meijia, Z., Hongjun, L., Zhao, L., Bao-Qiang, L, 2018. A facile method for simulating randomly rough membrane surface associated with interface behaviors. Applied Surface Science 427, 915 - 21.

Xiang, C., Genying, Y., Huachang, H., Yiming, H., Liguo, S., Hongjun, L., 2018. Impacts of morphology on fouling propensity in a membrane bioreactor based on thermodynamic analyses. Journal of Colloid and Interface Science doi: https://doi.org/10.1016/j.jcis.2018.07.030

Zhang, W., Ding, L, 2015. Investigation of membrane fouling mechanisms using blocking models in the case of shear-enhanced ultrafiltration. Separation and Purification Technology 141, 160-69.

Zhao, C., Xue, J., Ran, F., Sun, S, 2013. Modification of polyethersulfone membranes - A review of methods. Progress in Materials Science 58, 76-50. 


\section{Highligts}

- Transitional models for prediction of various membranes fouling have been developed.

- The membrane filtration parameters were characterized by a new approach of fouling.

- The dynamical surface phenomenon described well the kinetic of the fouling process.

- The experimental data of the validated model were submitted to rigorous statistical tests.

- Accuracy and efficiency of the models proposed in this study were tested and validated. 
Graphical abstract

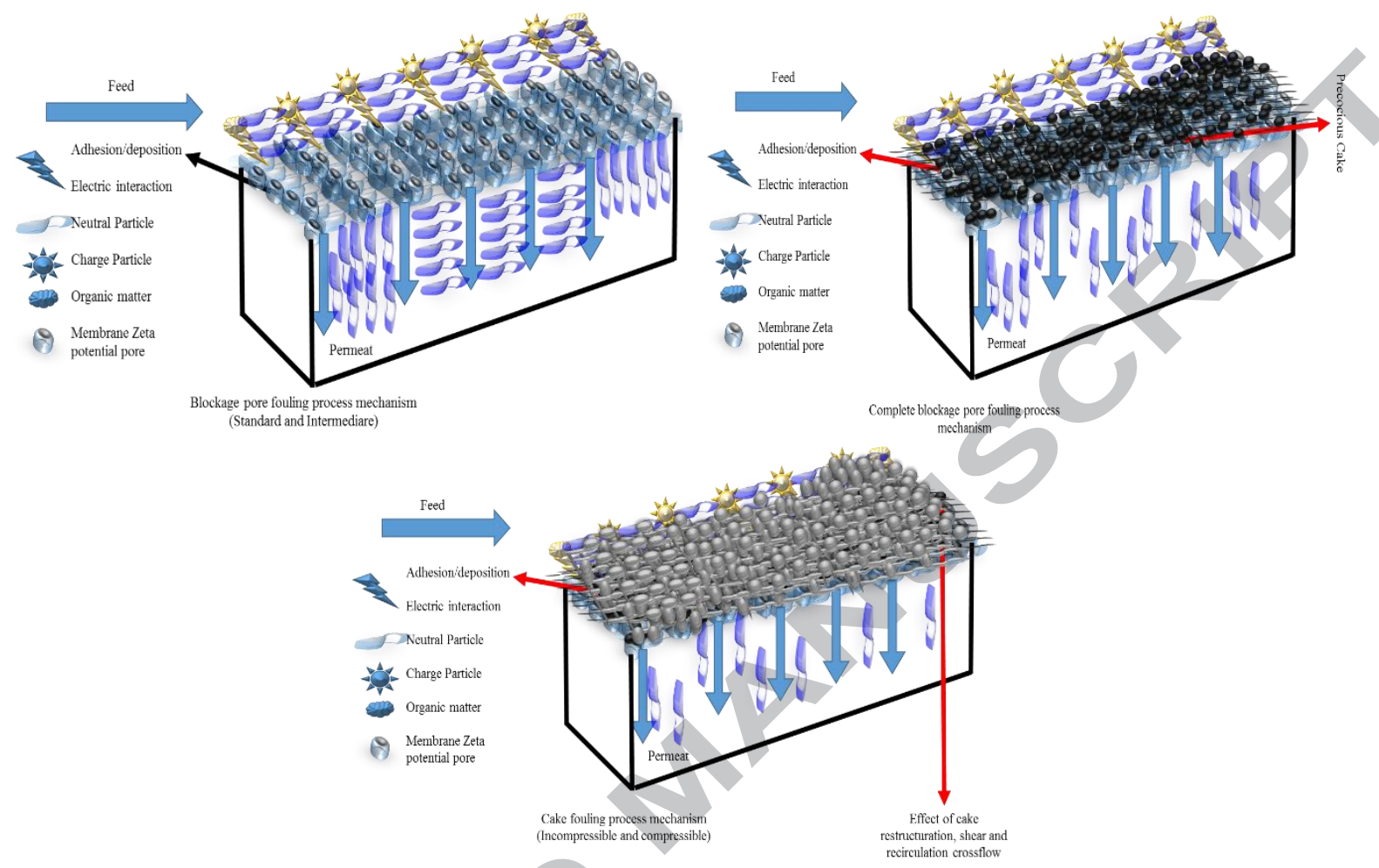

Fouling Process Mechanism in tangential filtration

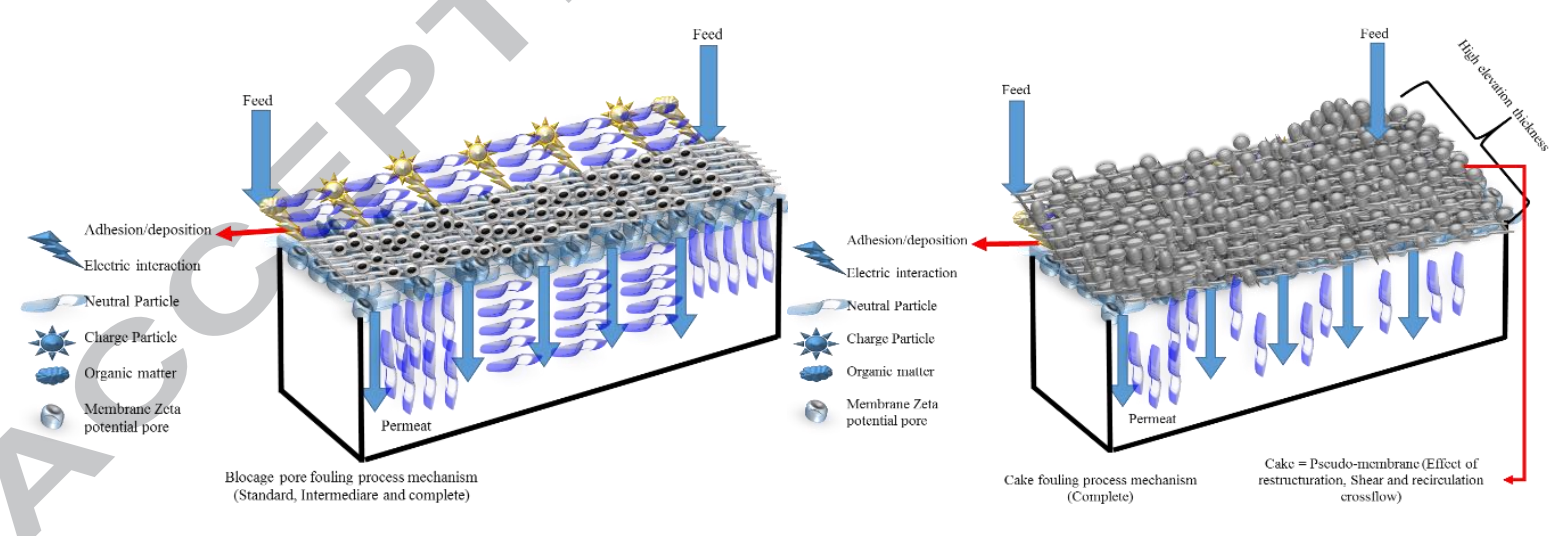

Fouling Process Mechanism in Frontal filtration 


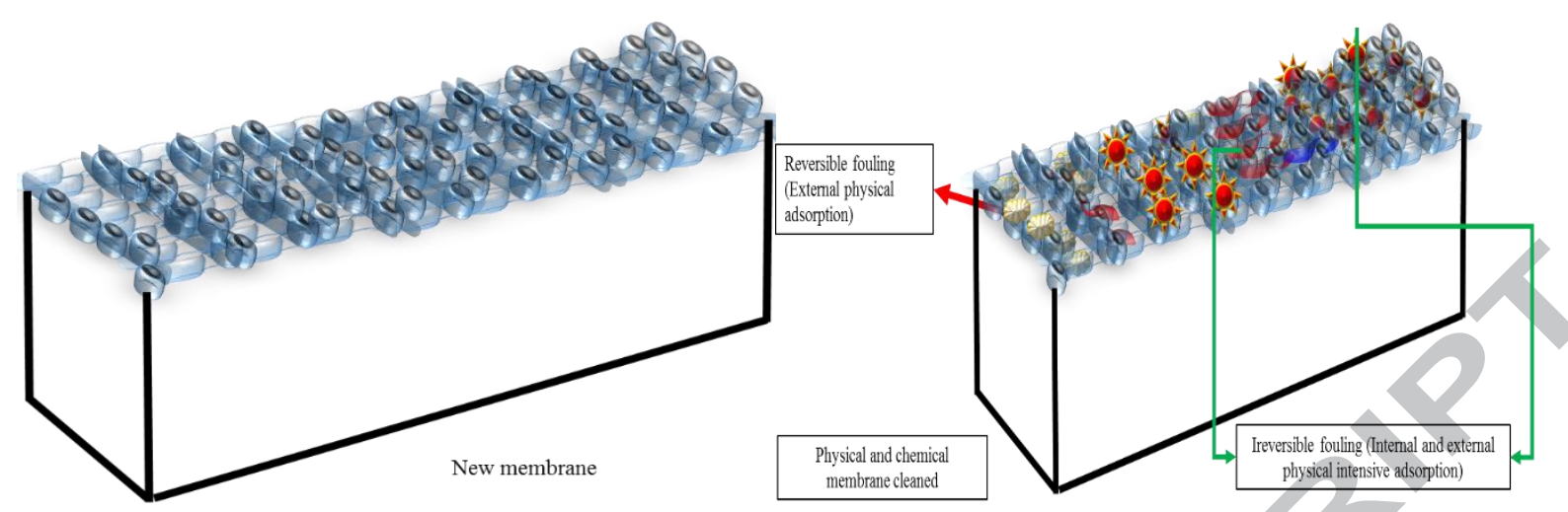

Membrane before and after filtration process 